$$
T / D / S N A--1585
$$

\title{
VOLUME TI
}

\section{PROGRAM PLAN}

\section{PART I - Technical Administration Documents}

NCS-211A

\author{
For SNP-1 Contract Yaar 1963 \\ 26 November 1962 \\ i,
}

\begin{abstract}
This report was prepared as an account of work sponsored by the United States Government. Neither the United States nor the United States Energy the United States nor the United States Energy
Research and Development Administration, nor any of their employees, nor any of their contractors, subcontractors, or their employees, makes any warranty, express or implied, or assumes any legal liability or responsibility for the accuracy, completeness or usefulness of any information, apparatus, product or process disclosed, or represents that its use would not infringe privately owned rights.
\end{abstract}

$\overrightarrow{0}$
$\frac{0}{\infty}$
$\frac{10}{2}$ 


\section{DISCLAIMER}

This report was prepared as an account of work sponsored by an agency of the United States Government. Neither the United States Government nor any agency Thereof, nor any of their employees, makes any warranty, express or implied, or assumes any legal liability or responsibility for the accuracy, completeness, or usefulness of any information, apparatus, product, or process disclosed, or represents that its use would not infringe privately owned rights. Reference herein to any specific commercial product, process, or service by trade name, trademark, manufacturer, or otherwise does not necessarily constitute or imply its endorsement, recommendation, or favoring by the United States Government or any agency thereof. The views and opinions of authors expressed herein do not necessarily state or reflect those of the United States Government or any agency thereof. 


\section{DISCLAIMER}

Portions of this document may be illegible in electronic image products. Images are produced from the best available original document. 


\section{VOLUAE II}

PART I

NERVA TECINICAL ADMINISTRATION DOCUMENTS

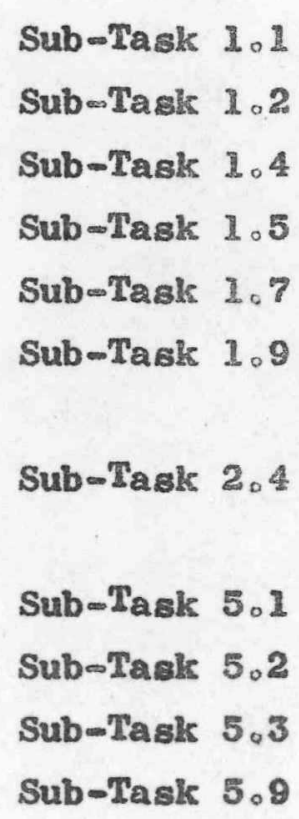

Engine System

Propellant Feed System

Thrust Chamber Assembly

Engine Controls

Pneumatic Powez Supply Syatem

System Irradiation Fxperiments

Diagnostic Instrumentation

STE LRP (Test Zone c)

STE LRP Cryogenies Laboratory (Test Zone A)

STE LRP (Test Zone H)

STE LRP Controls and Chenical Laboratory (B1dg. 2002)

Sub-Task 6.2 GFE LRP - A Area 


\section{TASK TITIE: BNIGINE SYSTEM DEVIEOPMEITI}

2. PURPOSE AND OBJECTIVES:

The objectives of this subtask at IRP are to perform the necessary engineering, fabrication and testing required to complete the Block I NERVA HOT BLEFED E-Engine (Non-Nuclear Components) design; continue the upgrading of the NERVA FX Engine (Non-Nuclear Components) design; complete the Generation II Simlator program; initiate testing on the Cold Flow Development Test System (CFDIS); and complete an analysis of the Hot Flow Development Test System (HFDTS). Gages will be designed and supplied to control subassembly and component interfaces. Requirements for functional or parametric acceptance testing of the non-nuclear NERVA E-Engines and FX Engines, and engine components and subassemblies prior to delivery to NRDS, AMR or the RIFT contractor will be analyzed and developed into a practical acceptance test system. A mockup assembly of the NIFRA engine will be initiated during CY 1963.

\section{RETLATED WORK AND BACTKGROUND:}

During the CY 1962 NERVA contract period, the major effort in this subtask was directed toward the Generation II simulator program and detailed. layout drawings of the NERVA Heated Bleed FX-Engine. The effort expended resulted in the design and fabrication of the Generation II, Mod I Simulator; the Generation II, Mod I Simulator test program plan was also initiated during this period. The layout work on the IX engine led to a series of simutaneous interdependent studies of the basic methods to be used in remote disassembly: gaging to insure compatibility of subassemblies at the assembly point; effect of design principles and form factor on handling, checkout concepts and special tooling. The complete layout reflects the conclusions reached by the end of CY 62. This development plans described below are a continuation of the effort expended during the NERVA Contract Year 1962 on Task 1.1, Engine 
System Development, but redirected towazd a Hot Bleed Engine System.

4. DESCRIYZTON OF WORK PROGRAM:

In fulfillnent of this subtask, the policy and procedurl requirements necessary to fulfill subtasks $2.6,4.1,4.2,4.3$, and 4.4 will be borne by the subtasls.

4.0 The sub-subtasks under this strbtask are:

1.1.0 - Engine System

1.1.1 - Generation II Simulator

1.1.2 - Development Test System

1.1.3 - Acceptance Test System

$1.1 .5-$ Mock-up

1.1.6 - Materials Evaluation

IRP will. contribute to all of the sub-subtasles with the exception of Sub-subtask 1.1.6 - Materials Ivaluation

4.1 Sub-subtask 1.1.0 - Ingine System

a. Engineering

(1) The Hot Bleed engine system development program during this period will consist of the following items:

(a) The Heated Bleed non-nuclear engine design work completed in CY 1962 will be incorporated, where applicable, into the non-muclear Hot Bleed FX Engine layout drawing. The initial non-nuclear Hot Bleed layout drawings will be available on 1 February 1963. Two revisions incorporating improvements in components, subsystems; and engine system designs are scheduled for completion on 1 June and 30 September 1963. The last revision will represent the engine configuration to be modified for release as the Block I E-Thgine. 
IRP NERVA Technical Administration Document Subtask Item 1.1

Contract Year 1963 NCS-211A 26 November 1962

(b) The design of the thrust stmucture and the adapter for the NTS engine test stand will be completed during this contract year. Tarly design effort vill include a remotely connected cable harmess connector study.

(c) The design of Master Pressure Vessel Interface gages for the NRX-A core-to-nozzle, reflector-to-pressure vessel and shield-to-pressure vessel interfaces will be completed 15 December 1.962.

(d) Design and fabrication drawings for the NERVA FX-Engineto-RIIT vehicle interface gage and the NTS engine test standto-test stand adapter interface gage will be completed 30 April 1962.

(e) Procedures and other required technical input for the NERVA Block I E-Ingine test plan, will be submitted to REON 15 June 1963. Contributions to Block I E-Ingine design specifications and NERVA IXX Engine model specifications will be prepared and submitted to REON 6 April and 15 June 1963. (f) The preliminary non-nuclear engine assembly - disassembly procedures developed during CY 1962 will be reviewed and revised. by 1 April 1963 and undergo additional revision prior to final relcase, which is to occur in CY 1964.

(g) Selection of long lead time material and components for ETS thrust structure and adapter vill be made by 15 May 1963. These items will be ordered to allow fabrication to start on 1 October 1963. Vendor qualifications will be surveyed and. liaison will be established and maintained. 
LRP NERVA Technical Administration Document Subtask Item 1.1

Contwact Yeax 1963 NCS-211A

26 November 1962

(h) Overall subtask administration and liaison with other subtasks, Azusa, Westinghouse, and other contractors will be continuously performed.'

b. Fabrication and Tooling

(1) The following items will be fabricated under Sub-subtask 1.1.0 - Engine System.

(a) The IMX- $\Lambda$ pressure vessel-to-reflector, core-to-nozzle, and pressure vossel-to-shield interface gages will be fabricated and shipped to Westinghouse by 1 April 1963.

(b) The NRX-A match-plates portion of the P.V. to NRX-A gages vill be shipped to Westinghouse from IRP 2 January 1963.

(c) The II ERVA IX-Ingine-ot-RIFI vehicle and EIS thrust structure-to-adapter interface gages will be fabricated and. shipped to the RITI contractor and NTS by 30 September 1963 .

c. Testing

(1) The testing effort on Sub-subtask 1.1.0 during this contract year will be limited to the overall administration and planning of the Subtask 1.1 test programs, the training of test personnel for assignment to NTS and support of the Cryogenics Laboratory in the areas of propellant handling and mechanical repairs.

4.2 Sub-Subtask 1.1.1 - Generation II Simulator

a. Engineering

(1) Complete the detail design and fabrication drawings required to modify the Generation. II, Mod I Simulator to the Mod IB configuration. This includes design of a simulated nozzle which approximates flow conditions and heat capacity of the NERVA hot 
LRP NERVA Technical

Administration Document

Subtask Item 1.1

Contract Year 1963 NCS-211A

26 November 1962

bleed nozzle during chill down. A proposed configuration and program plan, outlining the test objectives, was prepared prior to 15 October 1962 and will be revised as necessary and reissued by 15 March 1963.

b. Fabrication and Tooling

(1) Fabrication of the simulator hardware required under this sub-subtask will be limited to the modifications of the Mod I simulator components to the Mod IB configuration, and fabrication of a simlated nozzle assembly, simulated. prototype pump discharge line and modified turbine inlet system.

c. Testing

(1) The Generation II Mod I Simulator will be tested twice in October using cy 62 funds, and will be tested two more times during November.

(2) The Generation II, Mod IB Simulator test system will be installed in test stand C-8 which will be equipped with an altitude ejector system and a overhead simulated RIFT mun tank. Testing will begin in March and will consist of eleven (11) tests through 24 May 1963. See 1.1-(b) Chart. This program will evaluate the effect of the following parameters upon the engine system operation during the start transient:

(a) Initial Tank Pressure

(b) Initial Turbine Power Control Valve Position

(c) Nozzle Coolant Passage Minimum Area. 
IRP NERVA Technical

Administration Document

Subtask Item I.I

Contract Year 1963 NCS-211A

26 November 1962

4.3 Sub-Subtask 1.1.2 - Development Test Systems

a. Engineering

(1) The engineering effort of this subtask is

concerned with the Cold Flow Development Test unit,

which will be fully designed, and the long duration

Hot Flow Development Test System, which will be analyzed.

(a) The CFDIS will be designed in detail and

fabrication drawings vill be issued by 1 February

1963. The CIITS will incorporate the NERVA Hot-Bleed.

nozzle and skirt, and will employ advanced components

as they become available. A IIWI BI-B depleted core

will be assembled into the Pressure Vessel to re-

present the core flow dynamics.

(b) The CFDTS Test Program Plan and Test Objectives

will be completed and issued by 1 July 1963.

(c) The analysis for an extended duration Hot Flow

Development Test System will be completed and presented

for evaluation 31 January 1963.

b. Fabrication and Tooling

(1) The Pabrication under this sub-subtask will consist

of the manufacture of the engine components and assemblies

for the Cold Flow Development Test System.

c. Testing

(1) Testing of the CFDTS Mod I will be initiated in August 1963. This test program will consist of seven (7) 
IRP NERVA Technical

Administration Document

Subtask Item 1.1

Contract Year 1963 NCS-211A

26 November 1962

tests through September 1963. The purpose and objectives of this test program are a continuation of the objectives presented for the Generation II, Mod IB Simulator, utilizing a more sophisticated system with a KIWI BI-B depleted reactor core and available NIIRVA hardware. These tests will be conducted in test stand $\mathrm{H}-5$ which will be equipped with an overhead mun tank at the RIFI vehicle interface and an ejector.

\subsection{Sub-subta.sk 1.1.3 - Acceptance Test System}

a. Engineering

(1) The effort expended on this subsaubtasls will consist of

a detailed evaluation of the requirements for acceptance testing on non-nuclear engine components and subassemblies for the various blocks of NEIRVA engines. Emphasis will be placed on utilization of the existing quality control programs and the achievement of the required reliability in the component designs. The results of the evaluation will be presented in August 1963 with the IRP recomnendations for an acceptance test system.

b. Tabrication and Tooling

(1) No fabrication or tooling is planned for this contract period. c. Testing

(1) No testing is plamned under this sub-subtask for this contract period.

4.5 Sub-subtask $1.1 .5-$ Mock-Up

a. Engineering

(1) The engineering accomplished under this sub-subtask will be limited to the completion of an assembly drawing for the engine nock-up at IRP. The engine assembly procedures will be completed. 
IRP NERVA Technical

Administration Document

Subtask Item 1.1

Contract Year 1963 NCS-211A

26 November 1962

tests through September 1963. The purpose and objectives of this test program are a continuation of the objectives presented for the Generation II, Mod IB Simlator, utilizing a more sophisticated system with a KIWI BI-B depleted reactor core and available NERVA hardware. These tests will be conducted in test stand $\mathrm{H}-5$ which will be equipped with an overhead min tank at the RIFI vehicle interface and an ejector.

4.4 Sub-subtask 1.1.3 - Acceptance Test System

a. Engineering

(1) The effort expended on this subesubtask will consist of a detailed evaluation of the requirements for acceptance testing on non-nuclear engine components and subassemblies for the various blocks of NEIRVA engines. Emphasis will be placed on utilization of the existing quality control programs and the achievement of the required reliability in the component designs. The results of the evaluation will be presented in August 1963 with the IRP recomendations for an acceptance test system.

b. Tabrication and Tooline

(1) No fabrication or tooling is planned for this contract period.

c. Testing

(1) No testing is plamned under this sub-subtask for this contract period.

4.5 Sub-subtask $1.1 .5-$ Mock-Up

a. Engineering

(1) The engineering accomplished under this sub-subtask will be limited to the completion of an assembly drawing for the engine mock-up at IRP. The engine asscmbly procedures will be completed. 
IRP NERVA Technical

Administration Document

Subtask Item 1.1

Contract Year 1963 - NCS-211A

26 November 1962

A support fixture will be designed for the mock-up display.

b. Fabrication

(1) Fabrication will be linited to the manufacture of the mock-up support fixture and the assembly of the components as they become available. Scrapped or rejected hardware will be used.

c. Testing

(1) No testing is planned under this sub-subtask. 
LRP NERVA Technical

Administration Document

Subtask Item 1.2

Contract Year 1963 NCS 211A

26 November 1962

\section{TASK TITLE: PROPELLANT FEED SYSTEM}

\section{PURPOSE AND OBJECTIVES:}

The objective of this subtask at LRP is to develop a system capable of supplying propellant at the required flow rate and pressure to the NERVA engine thrust chamber. This task will be accomplished by performing all analyses necessary to design and fabricate chosen designs and conducting development programs on the components of the Propellant Feed System.

3. RELATED WORK AND BACKGROUND:

A liquid hydrogen pump has been under development at Aerojet for over two years. During Contract Phase $I$, bearings intended for operation at cryogenic temperatures in a radiation field were designed and a program to evaluate pump capability at NPSP values of less than 4 psi proved successful. During Contract Year 1962, bearing and pump tests have been continued and design and performance improvements have resulted. Design and development of valves, lines, and disconnects were initiated during Phase I and continued during Contract Year 1962. This task is a continuation of work initiated under Tasks $1.0,8.0$, 9.0 and 10.0 during the Phase I program and Task 1.2 during Contract Year 1962.

4. DESCRIPTION OF WORK PROGRAM:

In fullfillment of this subtask, the policy and proceduril requirements necessary to fulfill subtasks $2.6,4.1,4.2,4.3$, and 4.4 will be borne by this subtask.

$$
1.2-(1)
$$


LRP NERVA Technical

Administration Document

Subtask Item 1.2

Contract Year 1963 NCS 211A

26 November 1962

4.0 The sub-subtasks of this subtask are:

1.2.0 - System Assembly

1.2.1 - Lines and Disconnects

1.2 .2 - Valves

1.2.3 - Turbopump Assembly

1.2 .4 - Boost Pump Assembly

1.2.5 - Irradiation Tést Program

LRP will contribute to sub-subtasks 1.2 .0 through 1.2 .3$.

Work on sub-subtask 1.2 .5 has been transferred to sub-

subtask 1.9.5. No work will be performed on sub-subtask 1.2.4 during this contract period.

4.1 Sub-Subtask 1.2.0 - Propellant Feed System

a. Engineering

(1) Complete the E-1 propellant feed system design, analysis, and detail layout began in Contract Year 1962.

(2) Initiate and complete the preliminary acceptance test specifications for the propellant feed system components.

(3) Select the seals, bellows, and the remote disconnects for Block I, E-Engines.

(4) Initiate fabrication drawings of the propellant feed system assembly details for the Block I, E-Engines and complete fabrication drawings for the CFDTS.

(5) Test Plans will be coordinated with the CFDTS and Gen II Simulator planning activities. 
LRP NERVA Technical

Administration Document

Subtask Item 1.2

Contract Year 1963 NCS 211A

26 November 1962

(6) Test data from the CFDTS and Gen II Simulator

test program will be analyzed and incorporated into

the PFS design.

b. Fabrication

(1) Seals, remote disconnect flanges and bellows assemblies will be purchased for component testing in Contract Year 1963.

(2) Fabrication will be completed for E-1 configuration propellant feed system to be used on the CFDTS.

c. Testing

(1) Tests on the pump suction line, bellows, and remote disconnect flange components for the Block I Engines will be initiated and completed in Contract Year 1963. These tests will determine pressure drop and flexural and vibration amplitudes and frequencies at steady state flow conditions.

(2) Propellant feed system seal testing will continue through Contract Year 1963.

(3) TPA - pump suction line - TSOV system tests will be initiated in conjunction with TPA development testing to determine TPA performance at various TSOV inlet pressures and provide correlation of data from individual component development tests.

4.2 Sub-Subtdsk 1.2.1 - Propellant Feed System Lines and Disconnects a. Engineering

(1) Complete a drawing release of the prototype lines and disconnects for the CFDTS. 
LRP NERVA Technical

Administration Document

Subtask Item 1.2

Contract Year 1963 NCS 211 A

26 November 1962

\section{(2) Initiate and complete Block I E-Engine line}

design.

(3) Initiate detail fabrication drawings for Block

I Engines lines and disconnects.

b. Fabrication

(1) Initiate and complete fabrication of the following

E-1 engine configuration lines for the CFDTS:

(a) Pump Discharge Line

(b) Turbine Inlet Line Assembly

(c) Turbine Exhaust Iine Assembly

c. Testing

(1) Testing of E-I engine configuration lines will be accomplished on the CFDTS under sub-subtask 1.1.2.

4.3 Sub-Subtask 1.2 .2 - Valves

Tank Shut-Off Valve Assembly

a. Engineering

(1) Analyze test data obtained from laboratory, Gen

II Simulator and Cold Flow Development Test System tests.

(2) Review and improve the Configuration \#2 design for

the E-I engine to reflect experience gained in fabrication

and testing.

(3) Prepare a detailed test plan for the TSOV radiation

effects tests including purpose of tests, parameters

to be measured and operational requirements during tests. 
LRP NERVA Technical

Administration Document

Subtask Item 1.2

Contract Year 1963 NCS 211A

26 November 1962

(4) Analyze test and post-mortem data.

b. Fabrication

(1) (Complete fabrication in January 1963, of the

Configuration valves (E-I engine type) ordered during

Contract Year 1962).

(2) Fabricate one Configuration \#2 valve for use on

the Cold Flow Development Test System.

(3) Fabricate two (2) Configuration \#2 valves for 2 ti n

radiation effects testing.

(4) Provide additional cnadidate TSOV potentiometers

and solenoids for radiation effects testing.

c. Testing

(1) Initiate laboratory testing on the Configuration \#2 valves (E-1 engine type) in January 1963.

(2) The Configuration \#2 valve will be tested on the

Cold Flow Development Test System (See 1.1 TAD).

(3) Preliminary laboratory testing, to allow selection

of the flight engine design, will be $60 \%$ completed

by September 1963.

(4) Perform acceptance testing on one (1) Configuration

\#2 valve to be used in the radiation effects testing

program outlined in subtask 1.9.

Reactor Cooldown Valve Assembly

a. Engineering

(1) Analyze test data obtained from laboratory, Gen

II Simulator and Cold Flow Development Test System tests. 
LRP NERVA Technical

Administration Document

Subtask Item 1.2

Contract Year 1963 NCS 211A

26 November 1962

(2) Review and improve the design to reflect experience gained in fabrication and testing.

(3) Prepare a detailed test plan for the RCDV

radiation effects tests including purpose of tests, parameters to be measured and operational requirements during tests.

(4) Analyze test and post-mortem data.

b. Fabrication

(1) Complete fabrication in January 1963 of the valves ordered during Contract Year 1962).

(2) Fabricate a valve for use on the Cold Flow Development Test System.

(3) Fabricate two (2) Cooldown valves for radiation effects testing.

(4) Provide additional candidate cooldown valve potentiometers and motor actuators for radiation effects testing.

c. Testing

(1) Laboratory testing will be initiated on the Cooldown Valve Assembly in January 1963.

(2) Cooldown tests, which simulate actual operating conditions, will be initiated during CY 1963 in the Cryogenic Laboratory.

(3) Preliminary laboratory testing, to allow selection of the flight engine design, will be $60 \%$ completed by September 1963. 
LRP NERVA Technical

Administration Document

Subtask Item 1,2

Contract Year 1963 NCS 211A

26 November 1962

(4) Perform acceptance testing on one (1) cooldown.

valve to be used in the radiation effects testing

program outlined in subtask 1.9.

Turbine Power Control Valve

a. Engineering

(1) Prepare a development test plan for the Configuram tion \#2 to be used on E-1 engine.

(2) Analyze test data obtained from laboratory, Gen

II Simulator and Cold Flow Development Test System tests.

(3) Review and improve the design for increased temperatures and to reflect experience gained in fabrication and testing.

(4) Prepare a detailed test plan for the TPCV radiation effects tests including purpose of tests, parameters to be measured and operational requirements during tests.

(5) Analyze test and post-mortem data.

b. Fabrication

(1) Complete fabrication in April 1963 of the Configuration \#2 (E-I engine) valees for laboratory development testing.

(2) Fabricate one Configuration \#2 valve for use on the Cold Flow Development Test System.

(3) Fabricate one (1) Configuration \#2 valve for radiation effects testing. 
LRP NERVA Technical

Administration Documant

Subtask Item 1.2 NCS $211 \mathrm{~A}$

Contract Year 1963

26 November 1962

c. Testing

(1) Initiate laboratory testing on the Configuration \#2. valves in May 1963.

(2) The Configuration \#2 valves will be tested on the

Cold Flow Development Test System starting in August 1963.

(3) Perform acceptance testing on one (1) Configuration

\#2 valve to be used in the radiation effects testing

program outlined in subtask 1.9.

Purge and Emergency Cooldown Check Valves

a. Engineering

(I) Using design specifications previously established,

a design study will be made. This study will be com-

pleted in February 1963 and a design selection will be made at that time.

(2) A development and evaluation tbst plan will be prepared.

b. Fabrication

(1) Procure five (5) valves from commercial sources.

c. Testing

(1) Initiate laboratory evaluation testing in August

1963. The laboratory testing, to allow selection of the

flight engine design, will be $40 \%$ completed by the end

of September 1963. 
LRP NERVA Technical

Administration Document

Subtask Item 1.2

Contract Year 1963 NCS 211 A

26 November 1962

\subsection{Sub-Subtask 1.2 .3 - Turbopump Assembly Development Program}

\section{a. Engineering}

(1) The TPA development will be integrated with the entire propellant feed system. Feedback information from the early engine-simulator testing will be used concurrently with component test results to modify the turbopump component designs. The test data will be analyzed and documented and/or generalized plots of results will be made available including the following:

(a) The effect of pump inlet conditions and pump discharge flow restrictions on pumping performance, including pressure oscillations.

(b) The effects of turbine conditions and required pump power on turbine performance.

(c) The progress of hardware evaluation and development including mechanical vibations in the three axes, accumulated bearing life with the $\mathrm{LH}_{2}$-cooled TPA bearings, and cooling characteristics. (2) The designing of components will be closely coordinated to ensure the compatibility of components and remote handling procedures. The design studies for component improvements will be conducted concurrently with studies of remote handling requirements. Material studies, stress analysøs, etc., will be performed and the results will be incorporated as required. 
LRP NERVA Technical

Administration Document

Subtask Item 1.2

Contract Year 1963 NCS 211A

26 November 1962

The E-I configuration (Mark III Mod II) TPA design will be completed in November 1962. This configuration will be designed for remote removal and will enable engine operation at partial power. Tha power transmission will be designed in accordance with the latest design concepts and research results currently available to AGC.

Design activities will also include development configurations for improvement of axial thrust loads and for the improvement of the bearing coolant and power transmission designs.

Assuming that the derign criteria for the flight configuration TPA will be furnished to LRP in November 1962, the detail design drawings will be completed and released for fabrication in September 1963.

(3) Test plans will be formulated sufficiently in advance of the tests to permit the required reviews. Assistance will be given to the planning of the engine system design and testing where turbopump and turbopump components are involved. Test facility and instrumentation activitie will be appraised of the turbopump and turbopump component requirements:

(4) Liaison effort will be performed to coordinate bearing research and development results with turbopump and bearing designs. Available outside engineering 
LRP NERVA Technical

Administration Document

Subtask Item 1.2

Contract Year 1963 NCS 211A

26 November 1962

services will be utilized. Areas of consultation will include:

(a) Bearing dynamics.

(b) Elasto-hydrodynamic high pressure film analysis and research.

(c) Bearing material to $\mathrm{LH}_{2}$ coolant heat transfer analyses.

(d) Cage material research and analyses.

(5) Liaison effort will be performed as necessary to complete fabrication of turbopump assemblies; pump assemblies, turbine assemblies, and test bearings for use in the component development program and the engine test program.

(6) A turbine design analysis to determine the feasibility of redesign of the Mark III turbine for E-I engine, usage will be completed in January.

(7) Prepare a detailed test plan for the testing of turbopump bearings in a radiation environment. (8) Design a bearing tester suitable for testing in a nuclear radiation environment and including updated flight experimental (Mark IV) power transmission and bearing configurations.

(9) Analyze test and post-mortem data.

b. Fabrication

(1) Turbopump assemblies, pump assemblies and research bearing sets, in addition to TPA spare components, will

$1.2-(11)$


LRP NERVA Technical

Administration Document

Subtask Item 1.2

Contract Year 1963 NCS 211A

26 November 1962

be fabricated for use in the component development program during Contract Year 1963. In addition, turbopump assemblies and bearing sets will be fabricated to support Cold Flow Development Test System tests. Detailed fabrication schedules for all components are presented in the Hardware Demand Schedule.

Most of the turbopump assemblies fabricated in Contract Year 1963 will be of the E-l configuration. (2) (Fabrication of three (3) Mark II turbopump assemblies and three (3) Mark III, Mod I turbopump assemblies ordered in Contract Year 1962 will be completed early in Contract Year 1963).

(3) Provide the candidate bearings and necessary bearing tester repdacement parts to support the radiation effects testing program outlined in subtask 1.9.

c. Testing

(1) The development test program for the turbopump will include studies of mechanical life, reliability, performance, efficiency and the effects of vibrations, pressure oscillations and fluid dynamic conditions on adjoining engine components. The effects of the TPA inlet conditions on the pump head capacity curve, on turbine drive requirements and on vibrations and oscillations will be documented. Test objectives will include documentation of pump and turbine performance. 
LRP NERVA Technical

Administration Document

Subtask Item 1.2

Contraet Year 1963 NCS 211A

26 November 1962

including hot turbine drive, evaluation of $\mathrm{LH}_{2}$ cooled TPA bearings, and evaluation of the E-1 TPA design. Mark II (oil lubricated bearings) and Mark III ( $\mathrm{LH}_{2}$ cooled bearing) turbopump assemblies will be utjlized.

(2) Operation of an E-1 configuration turbopump for a minimum accumulation of ten minutes duration on one assembly at turbine inlet pressure and temperature in excess of NDC-IA values using $\mathrm{LOX}-\mathrm{H}_{2}$ GG combustion products as turbine drive fluid will be a requirement Contract Year 1963.

(3) One hour of accumulated roller and ball bearing endurance (one bearing each) at 2000 lb loads, at or above $19,700 \mathrm{rpm}$, and with $\mathrm{LH}_{2}$ cooling will be accomplished during Contract Year 1963.

(4) The effects of inlet conditions on pump performance and high frequency pressure oscillations will be docud" mented to the extent of the tests listed on the Test Schedule.

(5) Hardware evaluation and aevelopment tests directed toward development of the required power transmission endurance will include documentation of thrust, coolant flow, backvane flow, and hardware conditions at various turbopump inlet and exit conditions. 
LRP NERVA Technical

Administration Document

Subtask Item 1.2

Contract Year 1963 NCS 211A

26 November 1962

(6) In conjunction with the turbopump tests, turbine performance will be documented.

(7) Perform acceptance testing of various candidate bearings similar to those bearing sets that will be tested in a radiation environment. 
LRP NEIRVA Technical

Administration Document Subtask Item 1.4

Contract Year 1963, NCS-211A

26 November 1962

1. TASK TITIE: THRUST CHAMBER ASSEMBLY

2. PURPOSE AND OBJECTIVES:

The ultimate objective of this task is the development of a thrust chamber assembly for the NERVA engine. In this time period, effort will be directed toward continuation of design and development of TCA components (nozzle and extension, thrust structure, gimbal and pressure vessel assembly) for the hot bleed cycle engine to meet the design freeze date of December 1963 for the Block I E-Engine.

Additional objectives include design, fabrication, and testing of NRX A nozzles and pressure vessels, completion of the NERWI (Hybrid Nozzle KIWI-B-5 Pressure Vessel) Structural Test Frogram and development of the KIWI-B-6 Nozzle.

3. RETATED WORK AND BACKGROUND:

Design analysis, research, fabrication and test effort completed in the previous contract periods will be used, along with previous AGC rocket development experience, in establishing the direction of development effort. In many instances the work program will be a continuation of work initiated in the Contract Year 1963.

4. DESCRIPTION OF THE WORK PROGRAM:

4.0 Sub-Subtasks

$1.4 .0-$ Assembly

1.4.1 - Nozzle and Nozzle Extension

1.4.2 - Thrust Structure and Gimbol

1.4 .3 - Pressure Vessel 
IRP NERVA Technical Administration Document Subtask Item 1.4

Contract Year 1963, NCS-211A 26 November 1962

1.4.4 - Roll Control Assembly

1.4 .5 - KIWI-"B"

1.4.6 - Applied Research Frogram

1.4.7 - NRX-A and Reactor Backup Nozzles

1.4.8 - NERWI - ACFI Hydro-Test Program

1.4 .9 - KIWI-B-6 Nozzle

4.1 Sub-Subtask 1.4.0 - Assembly

Administration

In fulfillment of this subtask, the policy and procedural requirements necessary to fulfill subtasks $2.6,4.1,4.2,4.3$, and 4.4 will be borne by this subtask.

a. Engineering

(1) Technical direction, coordination, and review of all I'CA sub subtask will be provided on a continuing basis to insure that the work programs meet the objectives for this contract period.

(2) Dynamic analysis for design purposes and correlation with results from dynamic testing will be conducted on a continuing basis during the contract period.

(3) A dynamic Development Program Plan will be started in November 1962 and completed in December 1962.

(4) The necessary dynamic test tooling will be designed by March 1963.

(5) The detailed test plan for dynamic testing will be started in January 1963 and completed in June 1963.

$$
1.4-(2)
$$


IRP NERVA Technical Administration Document Subtask Item 1.4 Contract Year 1963, NCS-211A 26 November 1962

(6) The TCA layout for the Block I E-Engine will be prepared by September 1963.

(7) Design of a dummy reactor for the dymamic test program will be started in December 1962 and completed in February 1963.

b. Fabrication

(1) Fabrication of the dummy reactor and assembly of TCA will be completed in July 1963 for the TCA dynamic test program.

(2) Fabrication of tooling necessary to begin the TCA dynamic test program will be completed in June 1963.

(3) (Rework of an enjector and a XRI 87 Combustion Chamber will be completed.)

c. Testing

(I) A cynamic (vibration and shock) testing program will be inftiated in July 1963 and will continue into the next contract year. Test results will become available during the program and will be utilized for design modification, as necessary.

\subsection{Sub-Subtask 1.4.1 - Nozzle and Nozzle Extension}

a. Engineering

(1) The hot bleed nozzle will be designed based on data from the Hot Bleed port and. KIWI test results including scale model testing, material evaluation and stress and heat transfer

$$
1.4-(3)
$$


IRP NVERVA Technical Administration Document Subtask Item 1.4

Contract Year 1963, NCS 211 A 26 November 1962

analysis. This design will include a contour evaluation. Design changes will be incorporated as required to complete the design and initiate the frbrication of hot bleed nozzles. (2) The hot bleed extension will be designed.

(3) Heat transfer analysis, introducing results of hot: gas and inside tube film coefficient laboratory determinations, new gamma and neutron radiation heatup valves, and bleed port investigation results, will be continued.

(4) Fabrication liaison of nozzles and associated equipment will be provided.

(5) The layout for Block I Em Engine nozzle will be prepared.

(6) Design and analysis of an advanced concept nozzle will be completed.

b. Fabrication

(1) Six NERVA nozzles and two extensions for component development and combustion chamber tests will be fabricated.

(2) Two adaptors and three injectors for component development and combustion chamber tests will be fabricated . (3) Five full inlet lines and three thrust support structures for combustion chambers tests will be fabricated. (4) Two adranced concept nozales will be fabricated. (5) (Fabrication of two adapters and one injector for LoX- $\mathrm{H}_{2}$ testing of heated bleed nozzles will be completed.)

c. Testing

(1) Injector development tests will be performed in January 1963 utilizing XIR87 Combustion Chambers. 
IRP NERVA. Technical Administration Document Subtask Item 1.4

Contract Year 1963, NCS-211A

26 November 1962

(2) Hot Bleed and advanced nozzle development tests will be performed during Contract Year 1963. These tests will be performed to determine structural integrity, heat transfer characteristics, operational charseteristics and other pertinent information. Approximately $10 \%$ of these tests will utilize a hot bleed nozzle extension. The first nozzle will be used for start transient tests, followed by demonstration tests of operational characteristics. Ionger duration tests will be conducted in the Pressure Fed Test System.

(3) Hot Bleed port development tests will be conducted to provide design information for bleed port and control system lines. These tests will utilize the previously tested XIR87 TCA with a turbine power control valve.

\subsection{Sub-Subtask 1.4.2 - Thrust Structure and Gimbal}

a. Engineering

(1) The designs of the upper and lower thrust structures for Thrust Structure Stmetural. Test No. I were initiated. in the previous contract period and will be completed in October 1962.

(2) The Thrust Structure Structural Development Program, written in the previous contract period, will be revised in November 1962. 
IRP NERVA Technical Administration Document Subtask Item 1.4

Contract Year 1963, NCS-211A

26 November 1962

(3) A detailed test plan for the Thrust Structure Structural Test No. I will be initiated in January 1962 and completed in March 1963.

(4) A detailed test plan for the Thrust Structure Resonance Survey No. I will be initiated in January 1962 and completed in Apri1 1.963.

(5) The redesign of the upper and lower thrust structure for the Thrust Structure Structural Test No. 2 will be initiated in December 1963 and completed in January 1963. (6) A detailed test plan for the Thrust Stmcture Structural Test No. 2 will be initiated in March 1963 and completed in April 1963.

(7) Heat transfer analysis will be conducted during the contract year in support of design and stress analysis functions.

(8) Stress, weight and dynamic analysis will be conducted during the contract year in support of thrust structure and gimbal design functions.

(9) Gimbal design modifications will be made as required introducing data from test results, materials evaluation and stress, natural frequency, and hard vacuum effects analysis.

(10) The design layout for Block I El- Fngine thrust structure and gimbal will be prepared. 
IRP NERVA Technical Administration Document Subtask Item 1.4

Contract Year 1963, NCS-211A 26 November 1962

\section{b. Fabrication}

(1) Fabrication of an upper and a lower thrust structure for thrust Structure Structural Test No. 1 will be started in October 1962 and completed in March 1963.

(2) A testing ring to simulate the RIHI portion of the RIFT-NFRVA joing will be fabricated prior to April 1963 and a similar ring to simulate the pressure vessel portion of the thrust structure pressure vessel joint will be fabricated prior to April 1963 for Thrust Structure Structural Iest No. 1

(3) Dummy Gimbal Actuators which simulate mass, size and stiffness characat eristics will be fabricated prior to May 1963 for Thrust Structure Resonance Survey. No. I (4) Fabrication of upper and lower thrust structures for the cold Flow Development Test System and for use as engineering spares will begin in February 1963 and be completed in June 1963.

(5) Fabrication of an upper and a lower thrust structure for Thrust Structure Structural Test No. 2 will begin in January 1963 and be completed in May 1963. (6) Six gimbals for the gimbal development test and one for the TCA dynamic test program will be fabricated. Iwo gimbals for the Irradiation Test Frogram Subtask 1.9 will be fabricated. 
IRP NERVA Technical

Administration Document

Subtask Item 1.4

Contract Year 1963, NCS-211A

26 November 1962

c. Testing

(1) Thrust Structure Structural Test No. I will be conducted during April 1963.

(2) Thrust Structure Resonance Survey No. 1 will start in April 1963 and be completed in May 1963.

(3) Thrust Structure Structural Test No. 2 will be conducted during June 1963.

(4) Gimbal development tests to determine structural integrity, load capabilities and bearing friction under ambient and $\mathrm{IH}_{2}$ temperature conditions, will be performed. in Apriz and July.

4.4 Sub-Subtask 1.4 .3 - Pressure Vessel

a. Engineering

(1) The pressure vessel design for Structural Test

Series No. 2 and NRX-A will be started in November

1962 and be completed in December 1962.

(2) The design for an aluminum back-up pressure vessel

for NRX-A will be started in October 1962 and be completed. in Novenber 1962.

(3) The Pressure Vessel Structural Development Program, written in the previous contract period, will be revised in December 1962.

(4) A detailed test plan for Structural Test Series No. 2 will be initiated in April 1963 and will be completed in May 1963.

(5) A detailed test plan for the forward closure stress optimization program will be started in April and will be completed in May 1963 1.4-(8) 
IRP NERVA Technical

Administration Document

Subtask Item 1.4

Contract Year 1963, NCS-211A

26 November 1962

(6) The pressure vessel layout drawing for the Block IE Engine

will be initiated in August 1963 and completed in September 1963.

(7) Heat transfer analysis for transient and steady state conditions will be conducted during the contract year in support of design and stress ansiysis.

(8) Stress and weight analysis will be completed during the contract year in support of design effort.

(9) Mechanical properties evaluation of pressure vessel materials will be performed under sub-subtas k 1.4.6.

\section{b. Fabrication}

(1) The fabrication of a titanium pressure vessel for Structural Test Series No. 2 will be initiated in February 1963, and completed in May 1963.

(2) The fabrication of a titanium pressure vessel for the first Cold Flow Development Test System will be started in March 1963 and completed in June 1963.

(3) One aluminum NRX $-A$ back-up pressure vessel will be fabricated starting in December 1962. Fabrication will be completed in March 1963. Pressings for a second backup pressure vessel will be purchased in January 1963. (4) Three NRX-A titanium pressure vessel will be fabricated. One each will be completed in April, June and August 1963. 
IRP NERVA Technical Administration Document Subtask Item 1.4

Contract Year 1963, NCS 211-A 26 November 1962

(5) The fabrication of a pressure vessel for Structural Test Series No. 3 will be completed in September 1963. (6)( The fabrication of a pressure vessel for Structural

Test Series No. I initiated in the previous contract period, will be completed in December )

c. Testing

(1) (Structural Test Series No. 1 originally planned for and funded in the previous contract year will start in December 1962 and be completed in February 1963.) (2) Structural Test Series No. 2 will start in June 1963 and be completed in July 1963. (3) The forward closure stress distribution optimization program utilizing chemical milling will start in June 1963 and be completed in September 1963.

4.5 Sub-Subtask 1.4.4 - Roll Control Assembly

a. Engineering

(1) An analytical investigation will be conducted to determine the requirements of a roll control assembly.

b. Fabrication

Not Applicab le

c. Testing

Not Applicable 
IRP NERVA Technical

Administration Document

Subtask Item 1.4

Contract Year 1963, NCS 211 A

26 November 1962

4.6 Sub-Subtask 1.4 .5 - KIWI-"B"

a. Engineering

Not applicalbe.

b. Fabrication

Fabrication of two KIWI B nozzles, 2 adapters, and 2 Hybrid nozzles initiated in the previous contract year will be completed.

c. Testing

(1) KIWI-B and Hybrid nozzle development tests will be performed on nozzles fabricated with $C Y 62$ funds to determine structural integrity, and heat transfer characteristics.

4.7 Sub-Subtask 1.4.6 - Applied Research Program.

a. Engineering

(1) The Nozzle Jacket Development Program will continue during the 1963 contract period. Various cast jacket materials and primers will be evaluated for application to the tube bundle assembly. Method of application of titanium and possibly a heat treatable stainless steel jacket to the tube bundle will be a forged jacket for advanced nozzle design will be investigated. Fabrication development is also required. (2) The Braze Alloy Development Frogram will be continued during 1963. A complete netallurgleal evaluation will be performed on the selected braze alloys to determine 
IRP INERVA Technical

Administration Document

Subtask Item 1.4

Contract Year 1963, NCS $211 \mathrm{~A}$

26 November 1962

the necessary brazing parameters (time temperature cycles). Process engineering and fabrication follow-up work will be performed to establish optimum nozzle brazing and specifications.

(3) The TCA Material Evaluation Program will include:

(a) Material Physical and mechanical property evaluation.

(b) Material and process specifications.

(c) Development of inspection techniques and acceptance standards .

(d) Materials consultation.

(e) Drawing review for materials and processes.

(f) Materials testing.

(4) The Gimbal Materials Development Program will be reinitiated in October 1962 and continue during the 1963 contract period. Heat treatment and tensile testing, humidity and salt spray exposure, and dilatometric studies will be performed on candidate materials.

(5) The Pressure Vessel Méchanical Properties Test Program will be continued during the 1963 contract period. (6) The General Components Heat Transfer Analysis Program will be continued during 1963. Heat transfer analysis will be made of the thrust chamber, auxiliary and support structures, and the general engine components. It is planned to modify existing computer programs, where applicable, to account for nuclear heating, and within the practical limitations of time

$$
1.4-(12)
$$


IRP NERVA Technical

Administration Document

Subtask Item 1.4

Contract Year 1963, NCS 211A

26 November 1962

and budget to develop finite - difference solutions to the two

dimensional transient conduction in non-symetrical component

shapes with internal heat generation plus convective and

radiation cooling.

(7) The hot bleed nozzle extension materials program

will be conducted during the contracted period.

(8) A. n up-to-date file of the latest data on physical

and mechanical properties of candidate TCA materials

will be maintained throughout the contract year.

b. Fabrication

Not Applicable

c. Testing

Not Applicable

4.8 Sub-subtask 1.4.7 NRX-A \& Reactor Backup Nozzies

a. Engineering

(1) Engineering liaison will be provided to complete the fabria cation of the heated bleed nozzle initiated during contract year 1962 .

(2) Engineering liaison will be provided to fabricate and

deliver the NRX $-A$ nozzles and the Reactor Backup Nozzles.

b. Fabrication

(1) Fabrication of the heatead bleed nozzle initiated during contract year 1962 will be completed.

(2) Four NRX -A nozzles will be fabricated, one each in May, June, July and September.

(3) Three Reactor Backup nozzles will be fabricated, one in March and two in April. 
IRP NERVA Technical

Administration Document

Subtas k Item 1.4

Contract Year 1963, NCS 211A

26 November 1962

\section{c. Testing}

Acceptance tests of three NRX-A nozzles will be conducted.

4.9 Sub-Subtask 1.4.8 - NERWI - ACEI Hydro-Test Progrem

a. Engineering

(1) Iiaison with A.CFI and IASI, initiated in Contract Year 1962, will continue.

of the noz"zlewPressure Vessel joint

(2) An as-built stress analysi:/will be performed

(3) A preliminary data evaluation report will be issued during February 1963.

(4) The complete test report for the nozzle and interface joint will be issued by the end of Marach 1963.

b. Fabrication

There will be no fabrication in this contract year.

c. Testing

(The Structural testing will be completed $i^{n}$ January 1962)。

\subsection{Sub-Subtask 1.4.9 - KIWI-B-6 Nozzles}

a. Engineering

(1) The design of KIWI.B 6 will be completed in February.

(2) Engineering effort associated with a hydrostatic test of the B-6 nozzle - metal bot sm support plate - pressure vessel assembly and a cold flow distribution test of the Bub nozzle and metal bottom support plate will include: Design of test tooling, including a test stand and a support plate load. simulator, preparation of a detailed test plon, liaison, stress analysis, and engineering test reports as required. 
IRP NERVA Technical

Administration bocument

Subtask Item 1.4

Contract Year 1963, NCS-211A

26 November 1962

b. Fabrication

(1) Four B -6 nozzles will be fabricated with completion scheduled for the first unit in July 1963, Two nozzles are scheduled for completion in August and one in Septemb, er.

(2) The required test tooling for the hydrostatic test and the cold flow test will be fabricated.

c. Testing

(1) A. hydrostatic test will be performed in two phases during the month of July. Phase I will be a stress coat test with a minimum of instrumentation, while during Phase II approximately 180 channels of strain and deflection measurements will be recorded. (2) A cold flow distribution test will be conducted during the month of August to evaluate the metal bottom support plate B-6 nozzle configuration. A leak test of the test assembly will be performed before and after this test. (3) Four $\mathrm{IO}_{2}-\mathrm{IH}_{2}$ development tests of a B-6 nozzle will be performed in August 1.963. These tests will be performed to determine the structural integrity, heat transfer characteristics, and other information pertinent to operation of the nozzle. (4) Acceptance tests of two B-6 nozzles will be performed one in August and one in September. 
LRP NERVA Téchnical

Administration Document

Subtask Item 1.5

Contract Year 1963 - NCS-211A

26 November 1962

\section{TASK TITLE: ENGINE CONTROLS}

2. PURPOSE AND OBJECTIVES:

To continue the development of a reliable control system for the NERVA engine and to determine the sequence required by this system to insure proper operation of the engine。

3. RELATED WORK AND BACKGROUND:

This effort is related to the work being carried on under the present SNP-I contract in regard to the flow computer for the simulator, engine system analysis, and instrumentation development.

4. DESCRIPTION OF WORK PROGRAM

In fulfillment of this subtask, the policy and procedural requirements necessary to fulfill subtasks $2.6,4.1,4.2,4.3$, and 4.4 will be borne by this subtask.

4.0 The sub-subtasks of this subtask are:

1.5.0 - Control system

1.5.1 - System Analysis

$1.5 .2-$ Actuators

$1.5 .3-$ Amplifiers

1.5 .4 - Harness

$1.5 .5-$ Sensors

LRP will contribute to all of the sub-subtasks, except 1.5.1 System analysis during Contract Year 1963. The work under 1.5.5 - Sensors will be accomplished and reported under subsubtask 2.4 .3 
LRP NERVA Technical

Administration Document

Subtask Item 1.5

Contract Year 1963 - NCS-211A

26 November 1962

4.1. Sub-Subtask 1.5.0 - Control System

a. Engineering

(1) Techniçal direction will be provided for the control system design and development.

4.2 Sub-Subtask 1.5.1 - System Analysis

No LRP effort is planned

4.3 Sub-Subtask 1.5 .2 - A'ctuatórs

a. Englneering

in: $1: 1,1$

(1) Upon receipt of the design specification for the TPCV actuator and drive amplifiers a preliminary accept ance test plan will be prepared.

(2) The design criteria for the acceptance test equipment for the actuators and drive amplifiers will be prepared.

(3) Bendix actuators will be returned to Bendix for any maintenance or rework.

b. Fabrication

(I) The acceptance test equipment is fabricated under subtask 5.9 .

c. Testing

(1) Acceptance testing of TPCV actuators for the Gen II,.

Mod IB simulator, CFDTS, NTS KIWI B-6, and components development testing wlll be performed during this contract period.

4.4 Sub-Subtask 1.5 .3 - Amplifiers

a. Engineering

(I) Upon receipt of the design specification, a preliminary $1.5-(2)$ 
LRR NERVA Technical

Administration Document Subtask Item 1.5

Contract Year 1963-NCS-2IIA

26 November 1962

acceptance test plan for the temperature signal amplifier, pressure signal amplifier, temperature control amplifier, and pressure control amplifier will be prepared. (2) The design criteria for the acceptance test equipo ment for pressure and temperature signal and control amplifiers will be issued.

(3) Amplifiers will be returned to REON for maintenance and rework.

b. Fabrication

(1) The acceptance test equipment is fabricated under subtask 5.9.

c. Testing

(1) Acceptance testing of amplifiers for CFDTS will be completed.

4.5 Sub-Subtask 1.5 .4 - Harness

a. Engineering

(1) A preliminary design study of engine harness component requirements wil

(2) A study of vendor capabilities of actual engine harness components will be completed.

(3) Test data on actual engine harness components will be analyzed during this contráct period.

(4) An engine harness test plan will be issued.

(5) Jpon receipt of Englne Layout drawings and Westinghouse controls and instrumentation requirements the $E-1$ engine harness design will be initiated.

$$
1.5-(3)
$$


LRP NERVA Technical

Administration Document

Subtask Item 1.5

Contract Year 1963 - NCS-211A

26 November 1962

b. Fabrication

(1) Engine wiring harness components will be procured

for development testing.

(2) Engine wiring harness components will be procured

for Radiation Effects Testing in Subtask 1.9.

c. Testing

(1) Laboratory testing of engine harness components

will be initiated.

4.6. Sub $=$ Subtask $1.5 .5=$ Sensors

This work will be accomplished under sub-subtask 2.4.3

4.7 Sub-Subtask 1.5 .6 - Master Programmer

a.) Engineering

(1) Upon receipt of design specifications, a

preliminary acceptance test plan for the master programmer

will be completed and issued。

(2) The design criteria for the acceptance test equipment for the programmer will be completed.

(3) Liaison will be performed as necessary for programmers used on the Gen II simulators and CFDTS。

b. Fabrication

(1) Repair and modifications of the programmer used.

on the Gen II Simulators and CFDTS will be accomplished,

as required.

c. Testing

Not applicable 
LRP NERVA Technical Administration Docurent Subtask Item 1.?

Contract Year 1963 NCS 211A

26 November 1962

1. TASK TITLE: PNEUMATIC SYSTEMS

2. PURPOSE AND OBJECTIVES:

The purpose of this subtask is to develop a system eapable of supplying gas at the required llow sate and pressure (providing actuation, cooling, and purging of NERVA engine actuating devices) and to pressurize the RIFT vehiele propellant tank (providing an acceptable pump inlet pressure)。 This task will be accomplished by performing all analyses necessary to design and Iabrlcate chosen designs and initiate procurement of selected items.

3. RELATED WORK AND BACKGROUND:

Previous Aerojet experience with Titan tank pressurization systems will be utilized fully to design a reilable and effleient NERVA system。 The conceptual design accomplished during Contract Jear 1962 will be used as a basis for Contract Year 2963 effort.

4. DESCRIPTION OF WORK PROGRAM:

In fullflllment of this subtask, the policy and procedural. requirements necessary to fulf112 subtasks $2.6,4.1,4.2,4.3$, and 4.4 wi12 be borne by thls subtask. 4.0 - The subtasks of this subtask are:

1.7.0 - Paeumatie Systems

1.7.1 - Pneumatic. Systems Line Assemblies and Details

1.7.2 - Pneumatic Systems Controls

4.1 - Sub-Subtask 1.7.0 - Preumatie Systoms

a. Englnoering

(1) Using design criteris established during Contract 
LRP NERVA Technical.

Administration Document

Subtask Item 1.7

Contract Year 1963 NCS 211 A

26 November 1962

Year 1962, a study of existing vendor and AGC

pneunatie system component designs will be performed。

Modifications to the existing designs and/or new

component designs will be made as required.

(2) A preliminary Pneumatic Systems design analysí

and deta11 layout w112 be instiated and completed in

Contract Iear 1963.

(3) Coordination will be established with the cognizant

RIFI vehicle contractor personnel to establish the

Interface, enveloge and design requirements for the

tank pressurization systean.

(4) A layout of a pneumat1e supply system for the E-1.

engine assembly wi.11 be made。 The system will be

destgned to supply actuation gas to the various valve

and control rod actuators and w111 consist of compenents

which are adequate for the $\mathrm{B}-1$ engine test but are not

necessarily the flight prototypo configuration.

b. Fabrication

(1) Fabrication or procurement of Pneumat1s System

components will be initiated during Contract Yeax 1.963

to be used for development testing during Contract Year 1964。

c. Testing

(1) No component development testing will be conducted in Contract Year 1963 . 
LRP NERVA Technical

Administration Document

Subtask Item 1.?

Contract Year 1963 NCS $211 \mathrm{~A}$

26 November 1962

4.2 Sub-Subtask 1.7.1 - Pneumatic Systems Line Assemblies and Details

a. Bngineering

(1) Initiate and complete preliminary detail layouts

of line assembilies, aystem storage tanks and 11ae assembly supports。

(2) Indtiate and complete layout and fabrication drawings of line assemblies and components to be tested on the Cold Flow Development Test System during Contraet Teax 1964。

(3) Test Plans for component development testing w12.2 be prepared and 1ssued in September 2963.

(4) Initiate and complete layout and fabrication drawings of the storage tanks.

b. Fabrication

(1) Initiate fabrication of pneumatic systems Iines and detalls in Contract Yeas 2963.

(2) Inftiate Iabrication of test stand pneumatic connectors in Auguat 1963.

(3) Initiate and complete fabrieation of one storage tanks

C. Testing

(1) No component development testing will be conducted in Contract Year 2963.

4.3 Sub-Subtask 1.7.2 - Pneumatic Systems Controls a. Engineering

(1) Preliminary preumatic system control componeat 
LRP NERVA Technical Administration Document Contract Iear 1963 NCS 211A Subtask Item 1.7 26 Novembex 1962

\author{
Seale, Cheok Valves, Shutoff Valves - June 1963 \\ Disconnects, Seals, Filters - July 1963 \\ Relief Valves, Regulators - August 1963. \\ (3) Test plans for pneumatie systems control components
} w111 be prepared and 1ssued at the end of this contract persod.

b. Fabxication

(1) Fabrieation wild be inttsated on check valves, shutoff valves, fllters, gellef valves, acala, disconnects, and regulators during this contract year. C. Testing

(1) No testing wi.11 be conducted in Contract Ieas 2963. 
IRP NERVA Technical

Administration Document

Subtask Item 1.9

Contract Year 1963 - NCS-211A

26 November 1962

1. TASK TITLE: RADIATION EFFECTS TEST PROGRAM

2. PURFOSE AND OBJECTIVLS:

The purpose of this task is to perform the necessary irradiation experiments to demonstrate the sultability of various components of the NERVA engine when exposed to radiation equal to, or in excess of, that computed as maximum for engine life. The primary contribution of LRP to this task is to design, prepare and maintain NERVA component test packages for exposure to the vaxious radiation environments. The components to be tested are critical items whose improper functioning could seriously degrade operation of the engine, or could possibly cause complete failure of the engine system.

In addition, candidate instrumentation components will be exposed to the various radiation environments. Existing instrumentation used in measuring rocket engine diagnostic parameters has not been qualified for use in a radiation environment comparable to NERVA. Information available from past radiation effects work shows that upgrading and qualifying diagnostic instrumentation for NERVA will require consideration of component design, materials construction, redesign and qualification testing.

3. RELATED WORK AND BACKGROUND:

During CI 1962, the first mechanical irradiation test package was designed and fabrication was initiated. This test package includes a TSOV, TPCV, Bearing Tester and Static Flange Seal Assembly. Support equipment such as a $\mathrm{LH}_{2}$ dewar and pressurization system, a 400 cycle 
IRP NERVA Technical

Administration Documents

Subtask Item 1.9

Contruct Iear 1963 - NCS-211A

26 November 1962

power supply, vacuum jacketed line and recording and control equipment will be supplied by AGC-LRP and will be checked out, along with the test package, at IRP prior to installation at the Fort Worth Test Reactor. This special test equipment was funded in part in CY 1962.

4. DESCRIPTION OF WORK PROGRAM:

In fullfillment of thie subtask, the policy and procedural requirements necessary to fulfill subtasks $2.6,4.1,4.2,4.3$, and 4.4 will be borne by this subtask.

4.0 The sub-subtasks of this subtask are:

1.9.0 - Integration and Technical Management

1.9.1 - Reactor Design

1.9.2 - Criteria and Specifications

1.9 .3 - Radiation Analysis

109.4 - In-Pile Test

109.5 - Side-By-Side Tests

1.9.8 - STE-LRF NIRVA Radiation Effects Program

1.9 .9 - Operations

Al1 LRP participation in CY 1963 is in sub-subtasks 1.9.5 and 1.9.8. (See TAD Addendum for Sub-Subtask 1.9.8)

4.1 Sub-Subtask 1.9 .5 - Side-By-Side Tests

a. Engine ering

(1) Test planning will be prepared during this contract period for six mechanical tests to be conducted in CY 1963 and for seven mechanical tests to be conducted in CI 2964 。 
LRP NERVA Technical

Administration Document

Subtask Item I.9

Contract Year 1963 - NCS-211A

26 November 1962

(2) The design requirements and final design for each test package scheduled for testing in CI 1963 will be completed.

(3) The necessary control and instrumentation for each CI 1963 test will be finalized and the test and channel requests required will be prepared and submitted to REON for forwarding to General Dynamics, Fort Worth. Requirements for each test package instrumentation item will be made known to management of Subtask 2.4 for the ultimate procurement under 2.4 for installation on the test package required under 1.9 .5 .

(4) Test checkout and operating plans for each of the

CY 1963 tests will be completed.

(5) The test plans for irradiation testing of electrical

and instrumentation components will be coordinated with

the overall NERVA irradiation testing program. Detailed

test plans will be prepared under subtask 2.4 .

(6) Irradiation test fixtures, including special transo

ducer actuation devices, will be design for the irradia-

tion tests of transducers.

(7) Administration, planning and liaison engineering will

continue throughout the contract year.

(8) The requirements for continuation of radiation

effects testing will be determined and further tests will

be planned for CY 1964. 
LRP NERVA Technical

Administration Document

Subtask Item 1.9

Contract Year 1963 - NCS-211A

26 November 1962

b. Fabrication

(1) Fabrication and/or rework of the test equipment which houses the components to be tested during CY 1963 will be completed. (This includes completion of the fabrication started in CJ 1962 for equipment for Test No. 1)

(2) Nodification of the existing control console and the control rack will be accomplished for each testo (3) Test fixtures, including actuation and control devices, will be fabricated。

(4) Components to be tested will be fabricated and/or procured under the appropriate sub-subtasks.

co Testing

(1) AII experiments will be pretested at AGC-IRP at condition similar in all significant respects to Fort Worth ASTR or GTR tests, except for the radiation environment. Five pre-operational mechanical tests will be conducted at AGC-IRP in CI 1963.

(2) All electrical test systems, fixtures and instrumentation test items will be tested at AGC-IRP to insure satisfactory performance prior to shipment to the irradiation test facility。

(3) Each of the electrical and mechanical test systems scheduled for testing at Fort Worth during CI 1963 will be submitied to a checkout test at Fort Worth prior to activating the reactor。

$$
1.9-(4)
$$


Addendum to Subtask 1.9

LRP NERVA Technical Administration Document

Sub-Subtask Item 1.9.8

Contract Year 1963 - NCS-211

26 Novernber 1962

1. TASK TITLE: SPECIAI TEST EQUIPMENT - LRP NERVA RADIATION EFFECTS PROGRAM

2. PURFOSE AND OBJECTIVES:

The purpose of this subtask is to provide for continued design, procurement, modifications, fabrication, and installation of necessary special test equipment required during Contract Iear 1963 in support of the IRP NERVA radiation effects program.

3. RELATED WORK AND BACKGROUND:

During Contract Year 1962 considerable effort was directed towards STE design, procurement, fabrication and active construction of facilities at IRP for use in evaluating the NERVA LH 2 turbopump bearings. STE provided for this purpose included an $\mathrm{LH}_{2}$ dewar and its various related piping systems, power supply, and necessary instrumentation and control systems。

4. DESCRIFTION OF WORK PROGRAM

In fulfillment of this subtask, the policy and procedural require ments necessary to fulfill subtasks $2.6,4.1,4.2,4.3$, and 4.4 will be borne by this subtask.

4.0 STE design, construction management and mechanical, instrumentam tion and control STE.

This sub-subtask is under the cognizance of LRP and is additionally described in tabular form in Table III - 1.9.

4.1 Sub-Subtask 1.9.8 - STE Design, Construction Management and Mechanical, Instrumentation and Control STE 
Addendum to Subtask 1.9

IRP NERVA Technical Administration Document Sub-Subtask 1.908

Contract Year 1963 - NCS-211A

26 November 1962

Upon completion of construction efforts initiated during Contruct Iear 1962 the necessary equipment checkout operations will be performed at LRP concluding in the shipment of said equiprent to Fort Worth for participation in the NERVA Radiation Effects Test Program in support of the NRDS Program。

a. Design and Construction Management

(1) Design activities for Contract Yeax 1963 under this sub-subtask will include:

(a) Design modifications necessary to adapt mechanical equipment originally procured for test ing at NTS。

(b) Design of instrumentation and electrical systems for the provisioning of data acquisition and control systems at test site.

(c) Design of mechanical piping systems for the supplying of propellant and purge gases to the test pallet and supplying vessel.

(d) Design of necessary equipment modifications to accommodate test setup configuräion changes。 
ADDEN

Addendum to Subtask 1.9

IRP NERVA Technical.

Administration Document

Sub-Subtask Item 1.9 .8

Contract Year 1963 - NCS-2IIA

26 November 1962

(2) Construction Management during Contract Year 1963

will be provided as required throughout the fabrication

and installation of the Special Test Equipment. Efforts

will be taken to assure compliance with and incorporation

of any field modifications as may be required.

b. Mechanical, Instrumentation and Constrol STE

(1) Procurement, fabrication, installation, and activation

of the following STE will be accomplished during Contract

Year 1963:

(a) Modifications to $\mathrm{LH}_{2}$ vacuum jacketed supply line

and electrical power cabling connecting the $\mathrm{LH}_{2}$ 
Addendum to Subtask 1.9

LRP NEIZA Technical.

Administration Document

Sub-Subtask 1.9.8

Contract Year 1963 - NCS -211A

26 November 1962

supply vessel and notor generator to the test pallet. These modifications were necessary to adapt equipment originally procured for testing at NTS.

(b) Modifications to existing data acquisition and and control systems at the Fort Worth Test Site. Included axe the provisioning for instrumentation and control channels, control panels, and equipment racks. (c) Gaseous hydrogen, helium, and nitrogen supply piping systems and associated components to provide pressure regulation, supply, purge, and vent systems between supply vessel and test pa.let。

(d) System modifications necessary to accommodate test setup configuration changes.

\section{CONTRACT YEAR 1962 CARRY-OVER EFFORT}

Contraet Year 1962 Carxy=0ver Effort consists of those items of STE not completed during Contract Year 2962 and requiring completion as part of the Contract Iear 1963 effort. Active engineering design, procurement, fabrication, and installation has been initiated on all 1tems 1isted.

5.0 The Continued Sub-Subtask of this Subtask is: $1.9 .8-S T E$, S1de-By-Side Test Frogrem, NRDS Complete fabrication, installation, and test setup for checkout at LRF of equipment which was initiated in previous contract period for side-by-side testing at NRDS. 
Addendum to Subtask 1.9 LRP NERVA Technical Administration Document Sub-Subtask Itew 1.9.8 Contract Year 1963 NCS-211A. 26 November 1962

TABLE III - 1.9-1

VI. (AGC-IRP) TEST ZONE "G" - TEST STAND G-? (RADIATION EFFECTS PROGRAM)

A. MECHANICAL

1. Perform modifications to $\mathrm{LH}_{2}$ supply line between $\mathrm{LH}_{2}$ run vessel and test pallet and modification to electrical power cabling between motor generator and test pallet。

2. Provide for $\mathrm{GH}_{2}, \mathrm{GN}_{2}$, He supply to test pallet and run vessel, pressure regulation system and supply, purge and vent systems, and $\mathrm{IH}_{2}$ supply-to-run vessel rill system.

B. INSTRUMENTATION AND CONTROLS

1. Perform modifications to data acquisition and control system at LRF, including instrumentation and control channels to pallet, run vessel, and power supply. Modifications to test site G-? instrumentation to accomodate the modified control panels and equipment racks。

2. Perform modifications to accommodate test hardware configuration changes and necessary STE modifications to provide fox test site relocation. 
NRRVA Technical

Administration Document

Sub-Task 1.9

Contract Year 1963

15 November 1962

(IICS-211A)

I. TASK TITLE: SPLCTAL TTST LUUTPMENY - IRP JERVA RADTATION EFFECTS PROCRAY

2. PURPOSE AND ORTIRTIVIES:

The purpose of this sub-task is to provide for continued design, procurer ment, modfication, fabrication, and installation of necessary special test oquipment required dusing Contsact Zear 1963 in support of the IRP NERVA radiation effects progrom.

3. BELATED WORK AND BACKGROUND:

During Contract Yeer 1962 considerable effort was directed towards STE design, procurement, fabcioation and active construction of facilities at IRP for use in evaluating the NERVA IH/2 turbompunp bearings. STE provided for this purpose inciuded an $L_{\mathrm{H}}$ Dewer and its various related piping systems, power supply, and necassary instrumentation and control systans.

4. DISCRTPTION OF WORK PLAN

4.0 SWE design, construction managenent and mechanioal, instrumentation and control STE.

This submoubmtask is undex the cognizance of LRP and is additionally described in tebulax form in Teble $\mathrm{III}-1,29$.

4.1 SubmSub-Task 1.9.8 - STE Design, Construction Management and Mechanicol, Instarmentation and Control STE.

Upon completion of construction efforts injtlated during Contract Year 1962 the necessary equipment checirout operations will be performed at IRP conoluding in the shipment of said equipment to Fort Worth for participation in the IFRVA Rediation Effects Tegt Program in support of the NRDS Program。 
NERVA Technicel

Administreation Document

Sub-Task Item 2.9

Contract Iear 1963

15 November 1962

(NCS-212A)

a. Design and Constzuction Managenent

(1) Design activities for Contract Year 1963 under this sub-subtask will include:

(a) Design modifiaations made necessary to adapt mechanicel equipment originally procured for testing at WTS.

(b) Design of instrumentation and electrical systems for the provisioning of Data Acquisition and Control Systems at test sito.

(c) Design of meahanicel piping systems for the supply of propellant and prxige geses to the test pallet and supply vessel.

(d) Design of necessaxy equipment modifications to accommodate test setrup configuration changes。

(2) Constzruction management duxing Contract Year 1963 will be prow vided as required throughout the fabrication and installation of the Speciel. Test Equipmento Efforts will be telken to assure compliance with and incorporation of any field modifications as mey be required.

b. Mechanical, Thstrumentation and Control STE

(1) Frocusenont, fabrication, installation, and activation of the foljowing STE will be accomplished durelng Contract Year 1963:

(a) Modisications to $\mathrm{LHH}_{2}$ vacum jacketed appiy Iine and electrical. power cabling connecting the $\mathrm{LH}_{2}$ supply vessel and motor gonerator to the test palleto These modifieations were made necossery to adapt equipnent originsily procured for teating at IVS. 
MGRVA Technical Administration Doctment Sub-Task 1.9 Contract Yaar 1963 15 November 1962 (NCS-217A)

(b) Modifications to existing data acquiaition and control systeme at the Port Worth Test Site. Included are the provisioning for and instellation of instrumentation and control channels, contsol panels, and equipment racics.

(c) Gaseous hydrogen, helium, and nitarogen supply piping systems and associated components to provide pressure regulation, supply, purge, and vent systems between supply vessel and tast parloto

(d) Systen modifications necessaxy to accommodate test setup configuration changes. 
NLRVA Technical

Administration Document

Sub-Tesk 1.9

Contract Year 1963

15 November 1962

(ACS-221A)

5. COMURACT YEAR 1962 CARRY-OVBR JWFORT

Contract Iear 2962 Carry-over Fffort consists of those itans of STE not completed dussing Contract Year 1962 and requiring completion as part of the Contract Ioax 1963 effort. Active engineering design, proourenent, fabrication, and instanlation has been inftiated on all itams listed. 5.0 The eontinued Sub-Sub-Task of this Sub-Task is

1.9.8 STE, Radietion effects Progran, NPDS

Complete febrication, installation, and test setup for checlout at LRP of equipment which was 1nitiated in previous contract pexiod Lor sidemby-side testing at MRDS. 
$\longrightarrow R V A$

SPECIAL TEST EQUIPMIEN

TASK 1.9

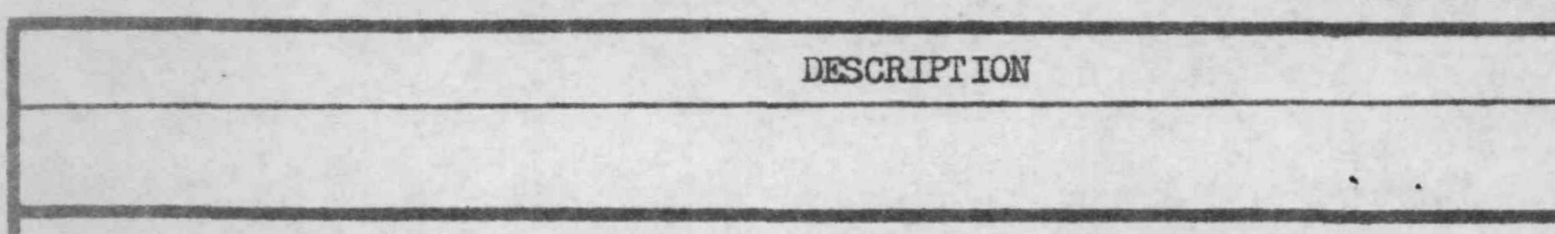

I. TEST ZONE "G" - TEST STAND G-7 (RADIATION EFFECTS PROGRAM)

A. Mechanical

1. Perform modifications to $\mathrm{LH}_{2}$ supply line between $\mathrm{LH}_{2}$ run vessel and test pallet and modification to electrical power cabling between motor generator and test pallet.

2. Provide for $\mathrm{CH}_{2}, \mathrm{GN}_{2}$ and He supply to test pallet and run vessel, pressure regulation system and supply, purge and vent systems, and LH2 supply-to-run vessel fill system.

3. Perform modifications to accommodate test hardware configuration changes and necessary STE modifications to provide for test site relocations.

Sub Total

\section{B. Instrumentation and Controls}

1. Perform modifications to data acquisition and control system at test site, including instrumentation and control channels to pallet, run vessel, and power supply. Modificatians to test site instmmentation and control panels and equipment racks.
Sub Total

TOTAL TASK 1.9 .8

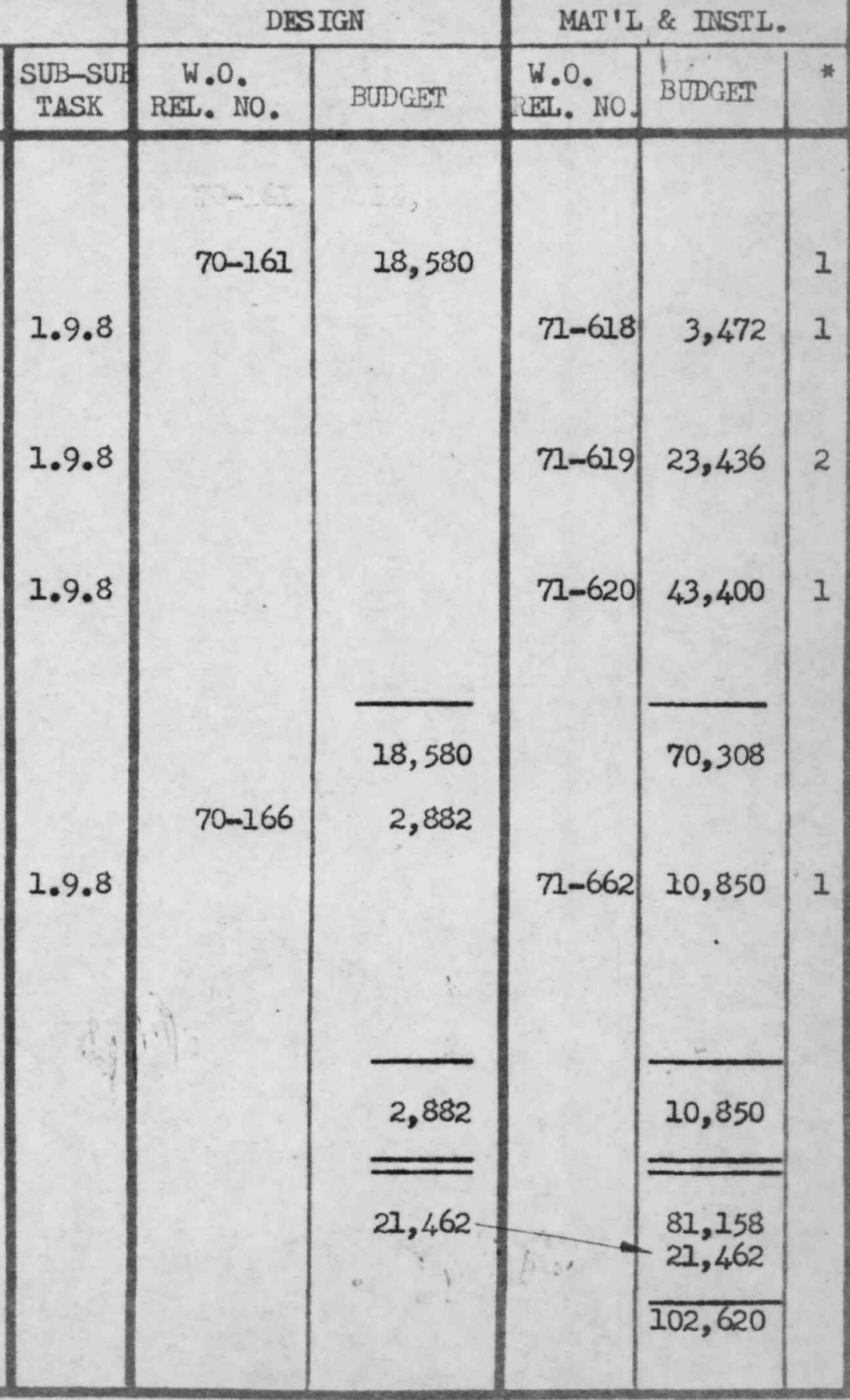


LRP NERVA Technical

Administration Document

Subtask $I_{\text {tem } 2.4}$

Contract Yaar 1963 - NCS-21IA

26 November 1962

\section{TASK TITLE: INSTRUMENTATION}

2. PURPOSE AND OBJECTIVES:

The purpose and objectives of this task are as follows:

a. To develop the ground and flight test instrumentation systems for diagnosis and control of the NERVA engine, excluding the reactor. These instrumentation systems must be suitable for measuring accurately and reliably all diagnostic and control parameters, such as temperature, pressure, flow, strain, position and acceleration, required in the NERVA engine over the expected range of radiation and temperatures.

b. Provide technical direction and monitor the development of the instrumentation required by the rarious NERVA engine component and subsystem development and test programs and coordinate the reactor instrumentation development program. Perform continuous integration of the design of the diagnostic and control instrumentation systems with the ETS-1 data acquisition systems. Maintain liaison with various activities throughout the country, pertaining to the development of significant and pertinent instrumentation. c. Subject to prior approval from SNPO $=$ C initiate development of instrumentation as required to meet the NERVA engine system, subsystem and component development programs.

\section{RELATED WORK AND BACKGROUND:}

Instrumentation used for measuring rocket engine parameters has not been developed for use in the high radiation and extreme temperature environment encountered in the NERVA engine. Present estimates of the

$$
2.4-(1)
$$


LRP NERVA $\mathrm{T}_{e}$ chnical

Administration Document Subtask Item 2.4

Contract Year 1963 - NCS-21IA

26 November 1962

NERVA vibration environment are no more severe than that experienced on Titan II, however difficulty is expected in qualifying engine transducers for the much longer (than Titan II) firing duration required of the NERVA engine. Information available from past radiation effects research shows that upgrading and qualifying diagnostic instrumentation for NERVA will require consideration of component design, materials of construction re-design and qualification testing. In addition, NERVA temperature measurements in the $\mathrm{LH}_{2}$ range requires accuracies presently obtainable only with special laboratory equipment and methods. During the Contract Year 1962 work has been initiated on development of temperature transducers capable of measuring liquid hydrogen temperatures accurately but which were not required to be tolerant of radiation. These transducers are essential in the development of the low NPSH hydrogen pump。

Work performed under this task is related to development of the control system under Task 1.5, the radiation effects program under Task 1.9 and, test stand instrumentation furnished under Task 5.0.

\section{DESCRIPTION OF WORK PROGRAM:}

In fulfilment of this subtask, the policy and procedural requirements necessary to fulfill subtasks $2.6,4.1,4.2,4.3$, and 4.4 , will be borne by this subtask。

4.0 The following sub-subtasks are included under this subtask:

2.4.0 - Diagnostic Instrumentation System

2.4.1 - Ground Test Instrumentation

2.4 .2 - Flight Test Instrumentation

2.4 .3 - Instrumentation Component Development

2.4.4 - Mechanical Component Irradiation Test Instrumentation

$$
2.4 \infty(2)
$$


LRP NERVA Technical

Administration Document

Subtask Item 2.4

Contract Year 1963 - NCS-21IA

26 November 1962

LRP will contribute to all the sub-subtasks listed。

REON will supply diagnostic parameter selection, interface

liaison, and component requirement specifications as related

to the above activities.

4.1 Sub-Subtask 2.4.0 - Diagnostic Instrumentation System

a. Engineering

Cryogenic Temperature Transducer Development

(1) Efforts initiated in Contract Year 1962 toward development of high-precision cryogenic temperature sensors and systems will be continued. The data from test stand use of sensor developed in CY 1962 will be analyzed for accuracy. These results and results from temperature measurement system tests described below will be used to verify that the desired capability for a cryogenic temperature measurement error of less than $\pm 0.05^{\circ} \mathrm{R}$ has been achieved. Calibration procedures will be prescribed which will optimize the measurement accuracy.

b. Fabrication

(1) Selected temperature sensors now under commercial development will be obtained for evaluation. Included among these are four quartz crystal sensors and four deposited film platinum resistance thermometers. Eight platinum resistance thermometers will be evaluated to establish a second source supply。

c. Testing

(1) Cryogenic temperature sensors for application in $2.4-(3)$ 
LRP NERVA Technical

Administration Document Subtask Item 2.4

Contract Year 1963 - NCS-21IA

26 November 1962

the test area which support the non-nuclear engine development, will be calibrated on the Test stand using the $\mathrm{H}_{2}-\mathrm{NEON}$ cryostat ordered under subtask 5.7 during 1962. These results will be used in analyzing the system accuracy。

4.2 Sub-Subtask 2.4.1 - Ground Test Instrumentation

a. Engineering

(1) The diagnostic instrumentation system, including installation in the $\mathrm{NRX}-\mathrm{A}=1,2,3$ engines will be designed based upon requirements established by the system design groups. Transducers and cabling will be selected on the basis of best available information. These components may not necessarily be radiation resistant. It is expected that the following parameters will be measured on the non-nuclear portions of the NRX-A engines based upon requests of the NRX-A system design groups:

Nozzle External Wall Temperature

Nozzle Coolant Inlet Pressure

Nozzle Coolant Inlet Temperature

Nozzle Coolant Outlet Temperature

Nozzle Coolant Outlet Pressure

Nozzle Strain Longitudinal

Nozzle Strain Transverse

Pressure Vessel Fluid Temperature

Pressure Vessel Wall Temperature

$$
2.4-(4)
$$


LRP NERVA Technical

Administration Document

Subtask Item 2.4

Contract Year 1963 - NCS-2IIA

26 November 1962

Pressure Vessel Longitudinal Strain

Pressure Vessel Transverse Strain

Pressure Vessel Vibration

Nozzle Flange Longitudinal Strain

Nozzle Flange Transverse Strain

(2) Where practical, installation design will be such as to minimize radiation damage and heating. Instrumentation for the NRX-A and for the NERVA engine mockups will be specified.

Engineering liaison will be provided in support of Task 1.l for instrumentation problems on the Generation II Simulator program and the Cold and Hot Flow Development Test System (CFDTS and HFDTS)。

Cooling and shielding requirements for the E-I engine transducers and associated components will be investigated for those instruments not radiation resistant. Selection of instrumentation system transducers will be initiated on the basis of CY 1963 irradiation test results.

b. Fabrication

(1) Diagnostic and controls instrumentation for the NRX-A engines, except reactor instrumentation will be fabricated and/or procured.

(2) It is expected that the following transducers will be procured for the non-reactor portions of the NRX-A engines:

Temperature Sensors

Pressure Transducers Strain Gages
Accelerometers

Connectors, Cables, Etc.

$$
2.4-(5)
$$


LRP NERVA Technical

Administration Document

Subtask Item 2.4

Contract Year 1963 - NCS-211A

26 November 1962

c. Testing

(1) NRX-A instrumentation system components will be tested to insure that they meet non-nuclear environmental specifications for reliability and accuracy based upon the expected conditions of vibration, temperature and pressure. Resistance tempterature transducers and other components requiring calibration before installation will be calibrated.

4.3 Sub-Subtask 2.4.2 - Flight Test Instrumentation

a. Engineering

(1) A minimum effort will be expended on problem peculiar to flight testing during CY 1963. A survey will be made of ground test instrumentation to determine if modification will be necessary for flight use.

4.4 Sub-Subtask 2.4.3 - Instrumentation Component Development a. Engineering

(1) Candidate components for NERVA control and diagnostic instrumentation system will be screened for radiation tolerance on the basis of material data, design, and available test data. NERVA radiation effects test data and pertinent radiation effects data from other sources will be analyzed. Appropriate components will be redesigned and/or modified to obtain improved reliability and performance. This effort will supply continuing input to the efforts on (a) component test planning; (b) NRX-A instrumentation system design; (c) the task of selecting and 
LRP NERVA Technical

Administration Document

Subtask Item 2.4

Contract Year 1963 - NCS-2IIA

26 November 1962

qualifying instrumentation components for the E-engines.

(2) Non-nuclear component tests will be planned for

evaluation and qualification of developmental and candidate

instrumentation system components. Of particular concern

will be the qualification of engine transducers in the heat

and vibration environment of the required long duration

NERVA engine firing time。

(3) Development of control system transducers such as

thrust chamber pressure and temperature will be carried

out in accordance with requirements established under the

engine controls subtask 1.5 .

(4) Component radiation effects tests will be planned for

evaluation and qualification of candidate instrumentation

system components。

b. Fabrication

(1) Transducers and their associated components will be purchased and/or fabricated for testing. It is expected that the following components will be procured for laboratory evaluation

Component

Pressure Transducers

Cryogenic Temperature Sensors

Accelerometers

Turbine Speed Transducers

Strain Gages

Position Transducers

Thermocouples

\section{Quantity}

8

4

8

2

10

6

10

$2.4-(7)$ 
LRP NERVA Technical

Administration Document

Subtask Item 2.4

Contract Year 1963 - NCS-211A

26 November 1962

(2) The following additional components will be procured for radiation testing:

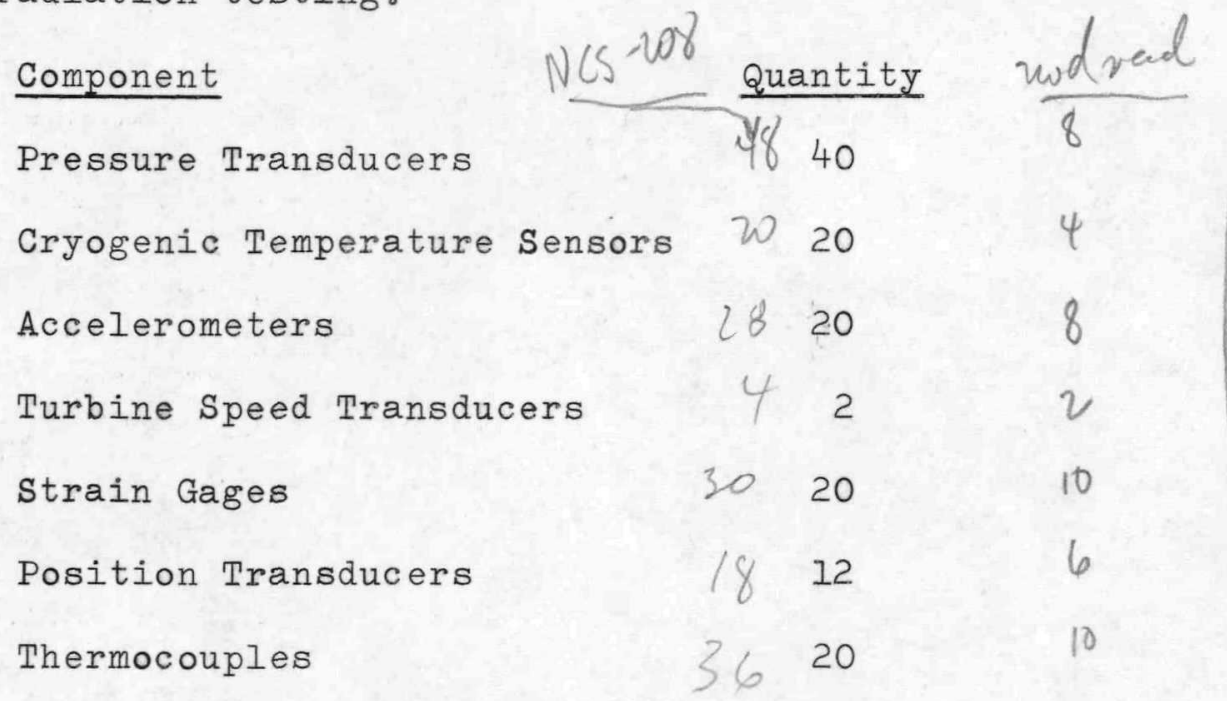

(3) Test fixtures required for radiation effects tests

will be fabrication under subtask 1.90

c. Testing

(1) Components selected for evaluation will be laboratory tested and when desirable, used on LRP component tests。 Surviving components will be eligible for further radiation effects testing。

(2) Components will be provided to subtask 1.9 for irradiation testing。 Required calibration and checkouts will be performed on irradiation test items at LRP prior to the irradiation test.

(3) Engineering test liaison will be performed with subtask 1.9 Engineers and with Irradiation Test Facility Personnel。 
LRP NERVA Technical

Administration Document

Subtask Item 2.4

Contract Year 1963 - NCSL211A

26 November 1962

\subsection{Sub-Subtask 2.4.4 - Mechanical Component Irradiation Test Package Instrumentation}

a. Engineering

(1) Test monitoring instrumentation will be specified and transducer mountings designed for 5 of the 6 mechanical components irradiation tests scheduled for Contract Year 1963 and for 7 of the tests scheduled for early Contract Year 1964. Data acquisition systems requirements will be specified. Instrumentation problem liaison will be conducted with the Irradiation Test Facility。

b. Fabrication

(1) Test monitoring instrumentation kits will be procured for the mechanical components irradiation test package. Instrumentation kits will be provided for five tests scheduled for Contract Year 1963 and seven test packages scheduled for early Contract Year 1964。

c. Testing

(1) Instrumentation kit components for the mechanical components irradiation test packages will be calibrated as required。 
IRP NERVA TEChnicaI Administration Document

Sub-Task Itent 5.1

Contract Ieax 1963

15 November 1962

(INCS-213A)

1. TASK TTILE: SPECIAI TEST EQUIPMENT - TEST ZONE "C" LRP PUREOSE AND OBJECTIVES:

The purpose of this sub-task is to provide for continued design, procurement, fabrication, and modifieation of the Special Test Equip= ment required during Contract $\bar{Y}$ ear 1.963 in Test Zone "C" for direct support of the NERVA R\&D Test Progrem. Frovisloning of this STE shall be accomplished in a timely manner, consistant with the program test schedulea, and in compliance with all project requirements specified。 All such systexs shall reflect the state-of-the-axt in performance capabilities and shall be provided at a minimun cost to the program. RELATED WORE AND EACKGKOUND:

The Pegt Zone "C" liquid bydrogen test facilities include Test Stands $\mathrm{C}-6, \mathrm{C}-7$ and $\mathrm{C}-8$. These-stands are specifically equipped for testing NERVA thruat chember components: turbopump assemblies, turbine power control and tank shutwoff valves: NERVA engine simulators, and development test systems. Each of these facilities has been constructed or modifted cluring prior contract years to proride a facility compatible with the requirements of the NERVA. Program. Each of the previous conversions bas been completed in a timely manner, resulting in a hydrogen test complex which provides the NERVA Program with high performanse test stand oapability. The Aerojet AFTRON Division performed all necessary architect-engineering services assodiated with the provisioning and modification of these test stands. These architect-engineering services are being render under the direot design eognizance of the NERVA Test Plaxning Department at IRP. 
iitp NERVA Technjeal Administration Document Sub-Task Item 5.1. Contract Year 1963

15 Novemiver 1962 ( $\mathrm{NCS}-211 \mathrm{~A})$

4. DESCRTPTION OF THE WORK PROGRAM:

$4_{0} 0$ The Sub-Sub-Tasks of this Sub-Task are:

5.3.0 - STE Degiga and Construction Managenent

5.1 .3 - Test Stand C-6 Mochanical S2E

5.1.4 - Tegt Stand C-6 Instrumentation \& Control STE

5.1.6 - Teat Stands Ga7, C-8 Mechanical STE

5.7.0 - Tost Stands C-7, C-8 Instrumentation \& Control STE

A17 of these sub-sub-tasks are under the cognizance of IRP.

Whese tasks axe additionaly describod in tabular form in

Table III $=5.10$ The policy and procedural requirements necessary to fulf111 Sub-tasks 2.6, 40., 402, 403, and 4.4 will be borne by this aub-task.

401 Sub-Sub-Tesk 5.1.0 - STE Design \& Construction Management

2. Mochanical-

Test Stands $\mathrm{C}-6, \mathrm{C}-7$ and Com are planned for continuous utiliaation during Cortrect Tear 1963. Design work for Test Stand Cu6 will be that necessary to serve the normal test operation neads, consisting prinarily of test atand modifications required che to test hardware configuration changeso

An ejector systen degign will be completed to provide simus lated a] ititude conditions at the sinulator and CFDrS turbine exharst and the nozzle exhaust prior to and during the testo Ing on Trest Stand Cons.

A how start transient LH/2 run vessel will be designed ron Instrllation above Test Stand Can to simulate vehicle starting conditions.

- Other dealgn effort wi1] be provided as needed to assure competibility of Test Stands Ca7 and Car to the tert progran. 
IRP NERVA TechniceI Administration Document Sub-Task Item 5.1 Contrect Year 1963 15 Noveraber 1962 $(\mathrm{NCS}-211 \mathrm{~A})$

b. Instrumentation and Control.

The instrumentation and control design of the Test Stand C-8 ejector system wi.h be accornplished early in this time pariod。

Design work required to modify any finstrumentation or control system to accomnodate test hardware configuration changes will be provided throughout the yoer whenever requested by test stand oporations parsonnel.

c. Construction Managoment

Construction managenent services will assure compliance of the contractor to the drawings and specifications provided and facilitate Incorporation of any field changes as ray be required.

40.2 Sta-Sub-Iask 5.1.3 - Test Stand G-6 Mochanical STE

In addition of the supersonic diffuser installation, which Was fundad durling Contract Year 1962 , a water-cooled thrust chamber assembigrotomdffuser adapter piping gystem will be fabricatod and installed on Test Stand Gmo.

other activity during Contract Iear 1963 w111 consiat of mochaniceI equipment modifiestions or additbions required to accomodate test herdware configuration changes. During the performance of a test program, contimed Improvement of testing procedures and resulting data Is desirabie. Staterof-themant test equipment modifications of a minax neture w11 be accornplished as the program progresses and nore experience With the IJERYA hasdwere is gained。

4.3 Subm Suburask 5.1.4 - Test Stand Con Instrumentation \& Control STE Activity during Contrect Iear 1963 will consist of instrumentation abd control equipment modifleations or additsons required to accommodate 
IRP NERVA TechnicaI Administration Document Subm Task Item 5.1

Contreact Ioar 1963

15 Norember 1962

(NCS-21]A)

teet hardware configuration changes and to improve the rellability and accuracy of the test data.

404 Sub-Sub-Task 5.1.6 - Test stand C-7, G-8 Machanical STE

The procurement, fabrication installation and activation of the following equipment wils, be initiated and completed during contract Y.a.5 1963.

\&. A complete twonstage ejector system for the simulator turbine exhaust and the main 1oad Iine, including ejectars, the GN2 (or other pumping fluid) piping system to provide the ejector motive Iluid, the ojoctor supporting structure and the ojsctor exhaust ducting。 b. A nou $\mathrm{LH}_{2} / \mathrm{LO}_{2}$ gas generator for use as an operating replacement to drive the TPA 3a Test stand C-7.

c. A new $\mathrm{LH}_{2}$ overhead Jun vessel, including vent, fild, pressurization and deluge systems fos Test Stand C -8 。

do Mochanicel eq2uipnent modifications or additions required to accormodate test hardware configuration changes。

4.5 Strbosuburask 5.1 .8 - Test Stands C-7, Cos Instrumentation and Control The procurament, fabrication, Installation and activation of the folo Iowing equipment will be initiated and eompleted dursing Contract Iear $2963:$

2. The electrical controls for operation of the Test Stand Car efector sy stom。

be Nev liquid level, pressure and temperature systems folf the over
head mu vessel to be installed on Test Stand C-8. G. Instrumentetion and control equipment modifieations ar additions required to accormodate test hardware configuration changes。 
IRP NERVA Technical Administration Document Sub-Task Item 5.1 Contract Ioar 1963 15 Novamber 1962 (HCS-211A)

5. CONTRACT YEAR 1962 CARPY -OVER BFFORT

Contract Iear 1962 Carryover Effort Eonsists of those items of SIE not completed during Contract Iear 1962 and requiring completion as part of the Contrect Year 1963 effort. Active engineering design, procurement, fabrication, and installation has been initiated on all items listed. 5.0 The continued Sub-Sub-Tasks of this Sub-Task are:

5.1.1 Test Stand G-6 Mechanicel STE. Complete modifications to existing STE, and fabrication and instajIation of propellant, deluge, and purge pip= Ing systans.

5.1.5 Test Stands C-7, C-8 Mechanical STE Complete fabrication and installation of test stand superstructure end associated piping and mechanical systems。

5.1.7 Test Stand C-8 Instmunentation and Control STE Conplete electricel control system installation and checkout. 


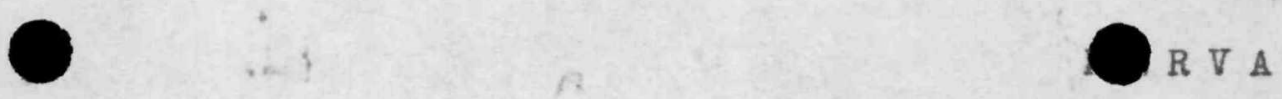

SPECIAL TEST EQUIPMIENT

TASK 5.1
TABLE

21 November 1962

CONTRACT YEAR

NCS $271 \mathrm{~A}$

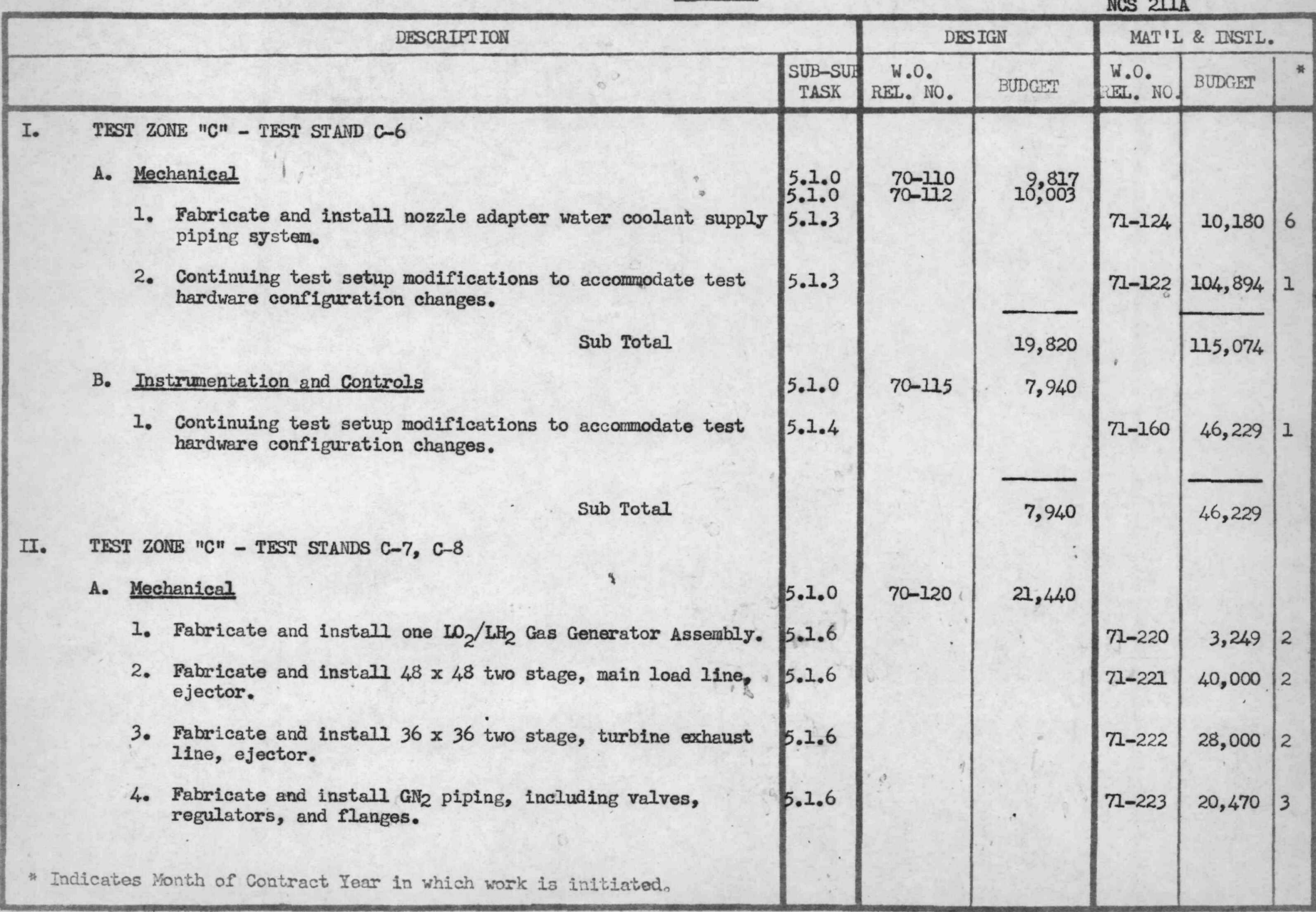




\begin{tabular}{|l|l|l|l}
\hline DESCRTPTION \\
\hline
\end{tabular}

5. Fabricate and install ejector horizontal support structure and work platforms.

6. Fabricate and install special ducting to adapt between simulator interface and ejector inlet.

7. Fabricate and install special 500 gallon, IH2 simulator, start transient vessel.

8. Fabricate and install vessel fill, vent, pressurization and deluge systems.

9. Modify existing test stand superstructure and simulator handling system.

10. Activation of ejectors and simulator start transient run vessel.

11. Continuing test setup modifications to acconmodate. test hardware configuration changes.

Sub Total

B. Instrumentation and Controls

1. Procure and install electrical controls for ejector and simulator start transient run vessel.

2. Fabricate and install liquid level sensing probe for simulator run vessel.

3. Procure and install transducers for simulator start transient run vessel.

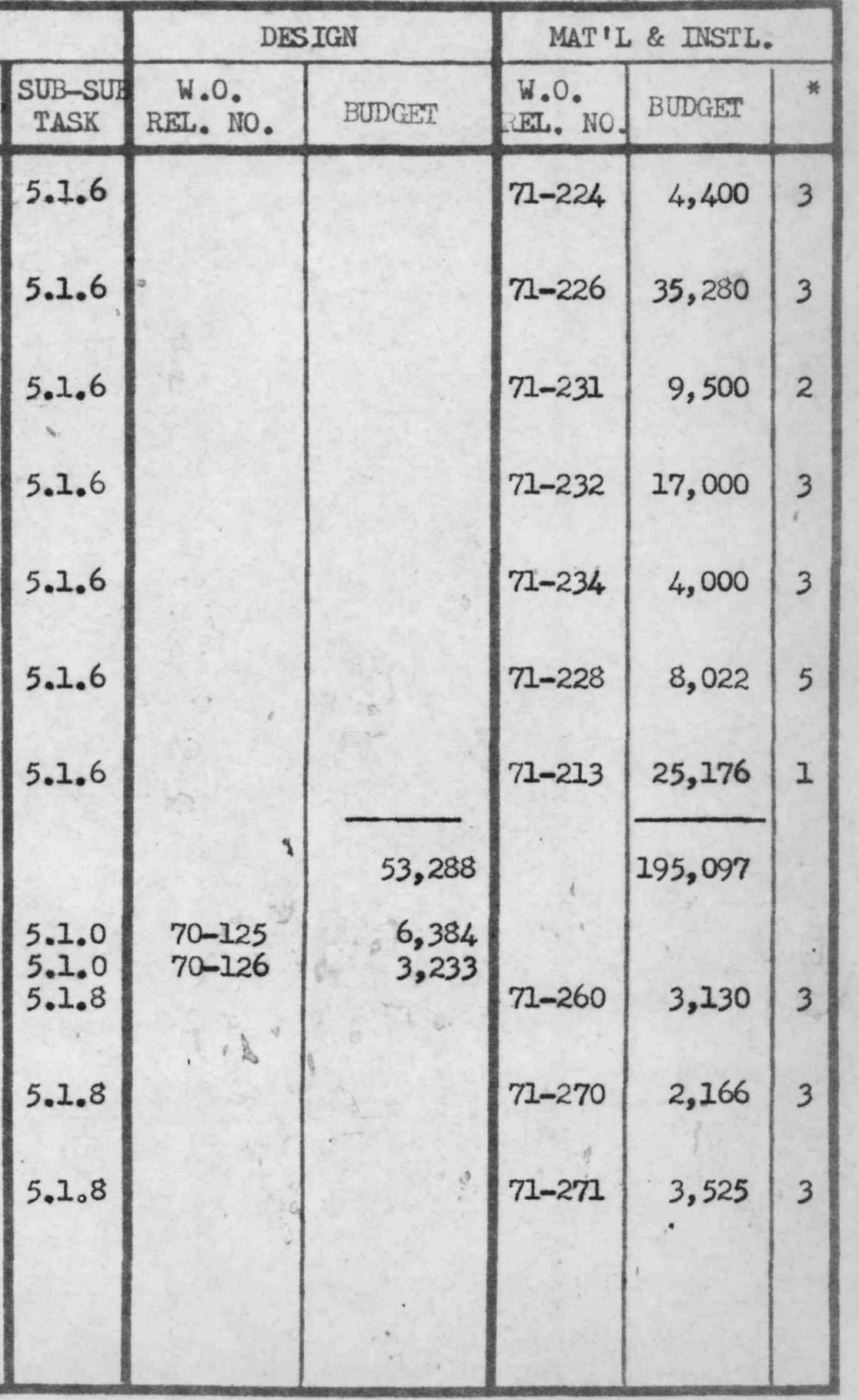

* Indicates Month of Contract Year in which work is initiated, 
NCS $271 \mathrm{~A}$

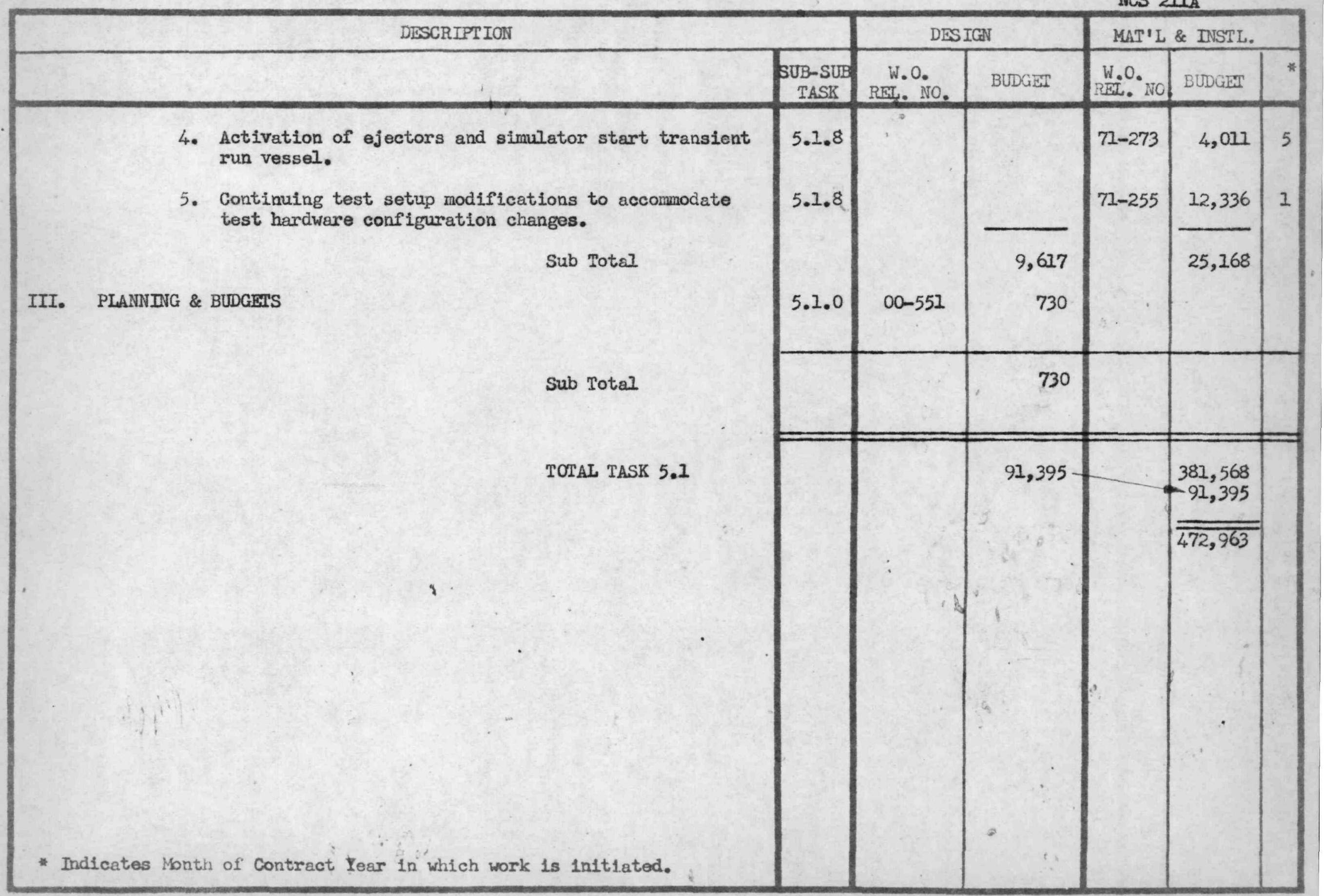


IRP NERVA Technical Adwinistration Document

Sub-Task Item 5.2

Contract Year 1963

15 November 1962

(NCS-2IIA)

1. TASK TITLE: SPECIAI TEST EQUIPMENT - TEST ZONE "A" CRYOGENICS IABORATORY, LRP

2. PURPOSE AND OBJECTIVES:

The purpose of this sub-task is to provide for contlnued design procurment, fabrication, instaliation and modification of the special Rest Equipment required during Contract Year 1963 in the Cryogenics Laboratory for direct support of the NERVA R \& D Program. A continued program of STE Eystem development for this laboratory fac1lity is necessary in order to continue serving the numerous component develop ment tasks, STE provisioning shall be accomplished in a timely manner consistent with the program development requirements? All systems shall seflect the state-of-the-art in porformance capabilities and shall be provided at a minimun costo

\section{REIATED BACKGROUND:}

The Cryogerics Laboratory was constructed for the NERVA Engine Program to implement research and devolopment in the field of cryogenios. The activities of this laboratory are being directed toward the developa ment of lfquid bydrogen engine components. The continued provisioning of this laboratory with special test equipment for testing materials and components in a liquld hydrogen environment will avold the necessity for improvised test setwrps in the existing engineering laboratories of in the high thrust test area. These special facilities and equipment w121 directly serve the reaeareh and development programs planned by the 
IRPNERVA Technical

Administration Dooument

Sub-Task Item 5,2

Contract Year 1963

15 November 1962

(NCS-227A)

Thrust: Chamber, Rotating Machinery, Systoms and Controls, Aerospace

Ground Equipment, Materials Engineering, and the Research Departments of the Ilquid Rocket Plant.

4. DESCRIPTION OF WORK PROGRAM:

4.0 The Sub-Sub-Tasks of thls Sub-Tagk are:

5.2.0 SoT.E。 Design and Construction Management

5.2o2 Cryogenics Laboratory Mechanical Special Test Equipinent

$5.2 .4 \quad$ Gryogenic Laboratory Instrumentation and Control Special Test Equipment

A11 of these Sub-Sub-Tarks are under the cognizance of LRP。

These tasks are additionaliy described in tabular form in

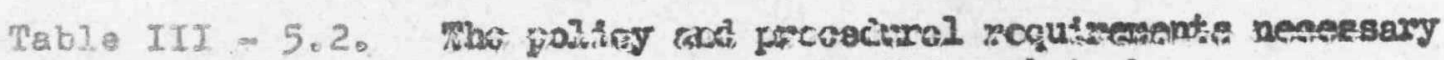

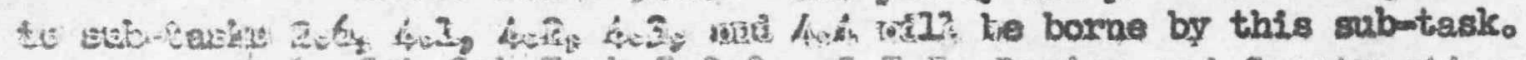

4.1 Sub -Sub-Task 5,2,0 $\infty$ S.T.E. Design and Construction Management

a. Mechanicel

(1) Final degign will be completed on the test bay. equipment requixed to initiate and support the development

test programe planned for the following components:

turbine power control valve, tank shutoff valve, and the

TPA hydrogen-cooled main bearing assembly. Additional.

design effort will be provided to serve the normal test

operations needs for the design of Test Bay modifleations

required due to test hardware configuration changes.

b. Instrunentation and Control

(1) The instrumentation and control design of the

transducers and lectrical control component test 
IRP NERVA TEChnICQI

Administration Doctment

Sub-Task Item 5.2

Contrect Iesp 1963

15 November 1962 .

( $\operatorname{MCS}-212 \mathrm{~A})$

setups will be accompliahod early in this contract years A hydrogen Leak measurement apparatus w17l also be designed. (2) Design work reguired to provide for modification of the instrunentation and control systems to accormodate test hardware conflguration changes HIII be provided throughout the yoar, whenever required by the test bay opexating conditions.

c. Constivet1.on Managersent

(1) Construction management exforts with regard to the procurement, fabsication and instajlation of special test equipment in the Gryogenic Laboratory iri1] be contInued during this contract period. Contract awards w171 be made to the 2owest qualified bidder. Roview of contractor plens, schectules, and cost breaisdown will be perpormed. (2) The installation of all equipnent modifleations will be coordinated with the test operating persomel and SLeld suparvision of such changes wi13 be provided. 4.2 Sub-Sub-Task 5.2.2 - Cryogenics Laboratory Mochanical Special Test

(1) During Contract Yeas 1963 the procurenent, faboication, and Installation of the following equipnent will be Initiated and completed:

(a) Two high speed bavring testers and a sparec. drive motor for bearing devalogenent in the Cryogenic Laboratory. Ten high spoed bearing testers for use in support of the radiation effects program, five of which are required for CI 1964 but must be conmitted during CI 1963 due to long lead manufacturing requirom ments. 
LRP NERVA Technical

Adminjstration Document

Sub-Task Item 5.2

Contract Year 1963

15 November 1962

(ics-212A)

\section{(b) Fabrication and installation of radiation effecta}

program hardwara checlsout and testing setup.

(c) An environnentol chamber for high and low temperature conditioning of component hardware.

(d) Special harchugre test certs and fixtures.

(e) A tank shut off valve test system, Including tank values and propellant lines.

(f) A turbine power catrol valve test system.

(g) An Lifh piping system from supply to the test specimen conteiners.

(h) Mechanicnl equipment modiffeations or additions required to accormodate test hardwore configuration changes.

\subsection{Sub-Sub-Task 5.2.4 - Gryogenic Laboratory Instrumentation and} Control Systans

(1) During Contrect Yeax 1963 the procurement, fabrication and Installation of the following equipment will be inj.tiated and completed:

(a) Transducers, fncluding torque, pressure, position temperature, load cells, accolerometers and flow meters.

(b) Special hydrogen loak measurement apparatus.

(c) Wiring and control system for the electrical component test sotup.

(d) Instrumentation and control equipment modifications or add tions required to accormodate test hardware configuration changes. 


\section{IRP NERVA Technical \\ Administration Document \\ Sub-Task Item 5.2 \\ Contrect Year 1963 \\ 15 November 1962 \\ (NCS-211A)}

5. COMTRACT TIEAR 1962 CARRYOVER GESORT

Contract Iear 2962 Carryover Effort consists of those 1tems of STE not completed during Contract Year 1962 and requixing completion as part of the Contract Year 1963 effort. Active onginearing design, procuremant, Labrication, and Installation has been injtiated on all Items listed. 5.0 The continued Sub-Sub-Tasks of this Sub-Task are:

5.2.1 Cryogenies Iraboratory Mechanical STE

Conplete fabrication and installation of hydrogen burnoff stackio

5.2.2 Cxyogenics Laboratory Mechanical STE Conplete fabrication and installation of special $\mathrm{LH}_{2}$ containess for conditioning specimens to cryogenic temperatureso

Complete fabrication and Installation of Special cryogenic heat transfer test apparatus.

5.2.3 Cryogenics Laboratoxy Instrumentation and Control STE Complete fabrication, installation, activation and chockout of data acruisition system. Complete fabrication and installation of Ilb Iran vessel 13quild leval sensing system. 


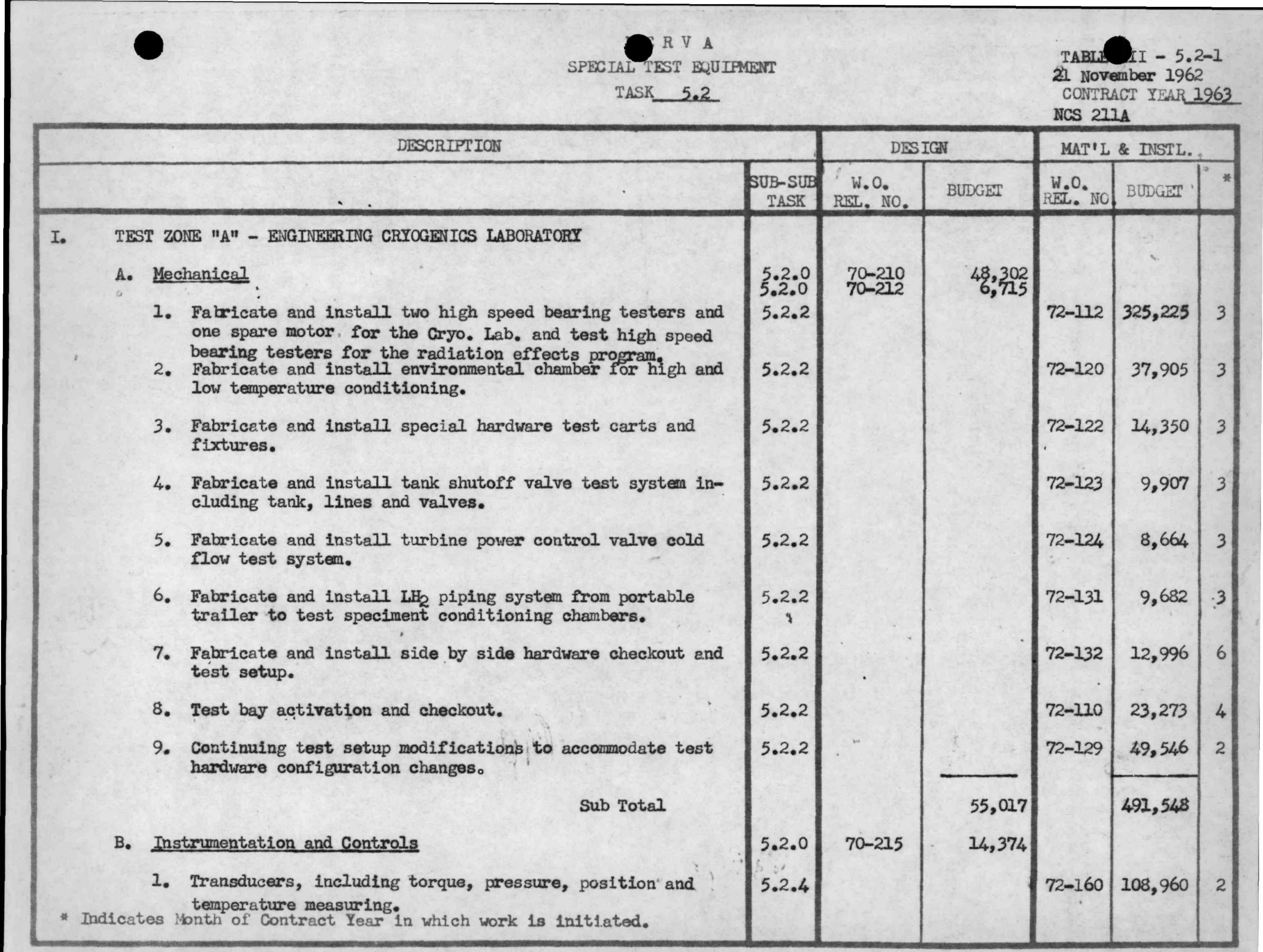


$R$ V A

SPECIAL TEST EQUIPMENT

TASK 5.2
TABI

21 November 1962

COMRACT TEAR 1963

NCS 211A

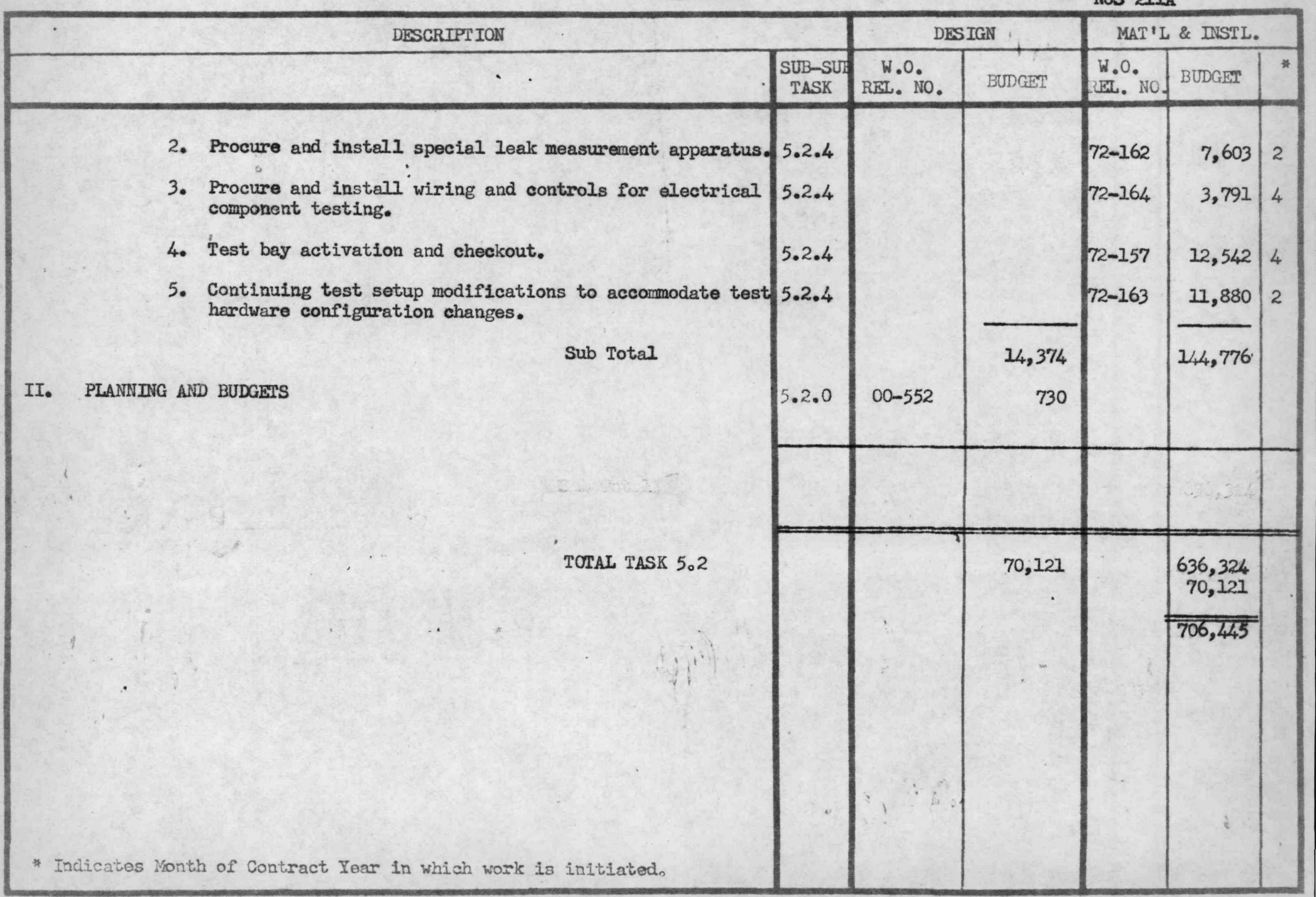


Zis NERVA Technical Administration Document

Sub-Task Item 5.3

Contract Year 1963

15 November 1962

(nCS-211A)

\section{PASK TITLE:' SEECTAI TFST EQUIFNENT - TEST ZONE H LRE}

\section{PURTOS F AID OBJECTIVES:}

The purpose of this sub-task its to provide for continued design, procurement, fabrication, installation and activation of Special Test Equipment required in Test Zone H during Contract Year 1963. Complew tion of STE funded and initiated during Contract lear 1962 will be accomplished. The STE described herein is in addition to that funded in Contract Year 1962 and is recuired to complete activation and permit gerational utilization of the rest Zone E Facility. The objective of this task effort is to provide a non-nuclear test facility capable of testing the NERYA exgine components, sub-systems and simulation engines consistent with the technical objectives imposed by the R\&D program

\section{RETATED WORK AND BACKGROUND:}

Pest Stands $H-4,-5$ and -6 , and the supporting equiprent in Test Zone "h" as modified and augmented will become the primary non-nuclear test facilities for the NERVA Program at the Liquid Rocket Plant. Design of the SPE modifications was initiated during Fhase I of this contract and proourement and installation was initiated in Contract Year 1962 The majority of the STE deaign and procurement activity in Test Zone "H" will be conyleted in Contract Year 1962. The balance of the design, procurement, installation and activation actirity will be completed during Contract Year 1963, except for the continuing activity necessary to support test stand modifications required due to test hardware con figuration changes 


\section{LRP NERVA Technic 2 Adrinistration Documents Subo-Task Item 5.3 Contreact Year 1963 15 Hovewber 1962 (NCS -211A)}

\section{DESCRIPTION OF WORK PROGRAY}

4.0 The Sub-Sub-Taskis of this Sub-Task are:

5.3.0 - STE Design and Construction Managenent

5.3 .2 - Test Zone "H" Mechanical STE

5.3 .8 - Test Zone "H" Mechanical, Instrumentation and Control STE

5.3.9 - Test Zone "H" Instrunentation \& Control STE

These tasks are additionally described in tabular form in Table III 5.3.- $A 11$ of these sub-subutrgks are under the cognizance of LRP. The policy and procedurel requirements necessary to sub-tasks 2.6, 4.1, 402, 4.3, and 404 will 401 Sub-Sub-Tasl6 5.3.0 - STE Design \& Construction Management

a. Mechanicer

(1) Mechanicel design activity for Contzact Iear 1963 in Test Zone "H" พบ21 include:

(a) Design of modifications to Test Stand $\mathrm{H}-5$ to accommodate CFDTS, facluding relocation of the Test $S_{t}$ and $G-8$ (Test Zone "Ci") ejector system and installation of a 1500 gellon simulator start transient Lif 2 sun vassel.

(b) Design of the STE necessagy to provide a bi-propellant, pressure fed, nozzle test systam for use in conjunction with the thrust chember assembly testing programo

(c) Design of a hydrogen hot gas heat exchanger to provide turbine motive fluid used in the TPA testing program. This facilifty to supply gaseous hydrogen at $20 \mathrm{lbs} / \mathrm{sec}_{\mathrm{o}} 2300^{\circ} \mathrm{F}$ to the TPA Turbine Drive Syster.

(d) Design work for test stand mechanical modifications made necessary by test hardware configuration changes after Teat Stand $15-48-5$, and -6 becone operational. 
IRP NERVA Technical Administration Documents Sub-Task Item 5.3

Contract Year 1963

15 November $196 \%$

(NCS-211A)

b. Instrumentation and Controls

(1) Instrunentation and control desiga activity for Contract Year

2963 in Test Zone "H" wil] include:

(a) Design of electrics 1 controls for $\mathrm{LO}_{2}$ supply flow control systam and TPCV test systomo

(b) Design of necessary control systems to accommodate relocated ejector systam and new sirmlator start transient vessel (RIFT tark botton configuration).

(c) Dewign of anslog computer checkout equipnent for CFDnS Program. This equipment wirll accomodate the relocated analog computar moved from Tast Zone "C".

(d) Dasign of a X-I Plotter for prechecking the function generators of the analog computer.

(e) Dasign of electrical controls for the hydrogen hot gas

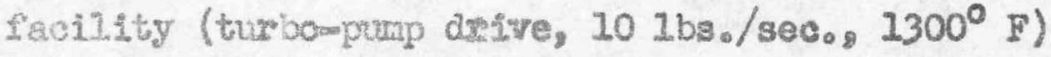

(f) Design of liquid level sensing probes for new simulator start trensient vessel.(RIFI tank bottom configuration)

(g) Dasign work for tsst atand instzrumentation and control modiflcations required by test hardware configuration changes after Test Stands Ho $4,-5$, and -6 become operational.

c. Construction Managenent

(1) Constmretion managenent servicas will assure awaro of contracts to qualffied low bidder and assure compliance of the contractors to the drewings and specifications provided, and to facilitate incorpora tion of any fleld changes as may be requirod. 


\section{IRP NERVA Technical Administiration Documents SubwTask Item 5.3 Contract Year 1963 15 November 1962 ( $\mathrm{NCS}-211 \mathrm{~A})$}

4.2 Sub-Sub-Iask 5.3 .2 - Test Zone "H" - Mechanical STE a. The ectivity under Sub-Sub-Task 5.3.2 during Contract Ioar 1963 พiาl include procurement, fabrefartion, Installation and activation of the following equipment:

(1) STE for GFDS 1ncluding relocation of Test Stand C-8 (Test Zone "G") ejector system and ingtallation of a 1500 gallon start transient $\mathrm{LH}_{2}$ Jun versal (RIFI tank bottam configuration)。

(2) Two gas generators to supply hot gas for use as a turbine drive Inedie for support of simalator and turbopump assembly testing。

(3) STE required for a bismpropellanty pressure fed, nozzle test system for use in the TCA Testing Programo

(4) Mechanicel equipment modifleations or additions required to acconmodete tast hardware conflguration changes.

\section{Mochabical}

4.3 Submsubm Task 503.8 - Tast Zone "hू" - Instrumentation and Controls STE 8. Activity to be initiated and completed under Sub-Sub-Task 5.3.8 duxing Contract Year 1963 includes the fabrication instarlation and activation of the following equilpment:

(1) SIE necessary to provide a hydrogen hot gas heat exchanger。 This facility wing be utilized in the TPA testing prograng supply geseous $\mathrm{H}_{2}$ at $20 \mathrm{Ibs} / \mathrm{sec}_{0} 13000 \mathrm{~F}$ to the TPA Turbine Drive System.

(2) Bectrical Ingtrumentation and control STE for operation of the hydroger hot gas feclility (10 Ibs。/Secog $1300^{\circ} \mathrm{F}$ )。

404 Sub-Sub-rask 503.9 - Test Zone "y a. Actifity to be initiated and complated under Sub-Sub-Task 5.3.9 during Contrect Year 1963 inclusies the fabrleation, Installation, and activation of the following equipment: 


\section{LRP N. RVA Techanicel Adminis tration Document s Subusask Item 5.3 \\ Contract Iear 1963 15 November 1962 (NCS-21]A)}

(1) Electrical controls to operate the $\mathrm{LO}_{2}$ supply flow controls systam and TPCV Test System。

(2) Instiumentation and control system STE to accommodate the relocatod Test Stand $\mathrm{C}=8$ ejector systein and the new simulator start trangient vessal.

(3) Analog computars checlsouts equipment, Including a Xo-Y Plotter

for prechecking the function generators of the cornputer.

(4) Liquid level sensing probes for hydrogen measuremento

(5) Instrmentation and controls equipment modifications or addis tions required to accommodate test hardware configuration changes. (6) Test Stand activation for tuabo-pump - assembly and simulated angine testing。 


\section{IRP NERVA TEChnical}

Administration Document Sub-Task Item 5.3 Contract Year 1963 15 November 1962 (NCS-211A)

\section{GONTRACT TEAR 1962 CARRYOVER EITEORT}

Contract Year 1962 Carryover Exfort consists of those Items of STE not completed during Contract Iear 1962 and requiring completion as part of the Contract Year 1963 effort. Activo engineering design, procurement, febrication, and Installation has been Initiated on all itams listed.

5.0 The continued subm-Sub-Tasks of this Sub-Task are:

Test Zone H Mechanicel STE

Complote fobrication and installation of the following:

5.3.4 (a) $\mathrm{CH}_{2}$ pipling and components

(b) Diffuser positioning equipment and support structure

(c) Hardware handling system

(d) Hyciraulic supply system

(e) Necessary LIt/2 piping system components

5.3.5 Difruser and Bngine Chamber Vessel

Test Zone II Instrunontation and Control STE

Complete tho followings

5.3.7 Degign, fabrication and Installation, activation, and checkout of Test Zone H Instrumentation and Control Systen. 


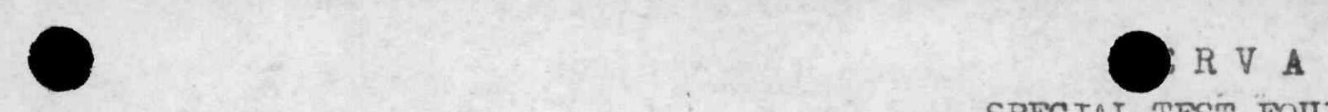

NCS 2114

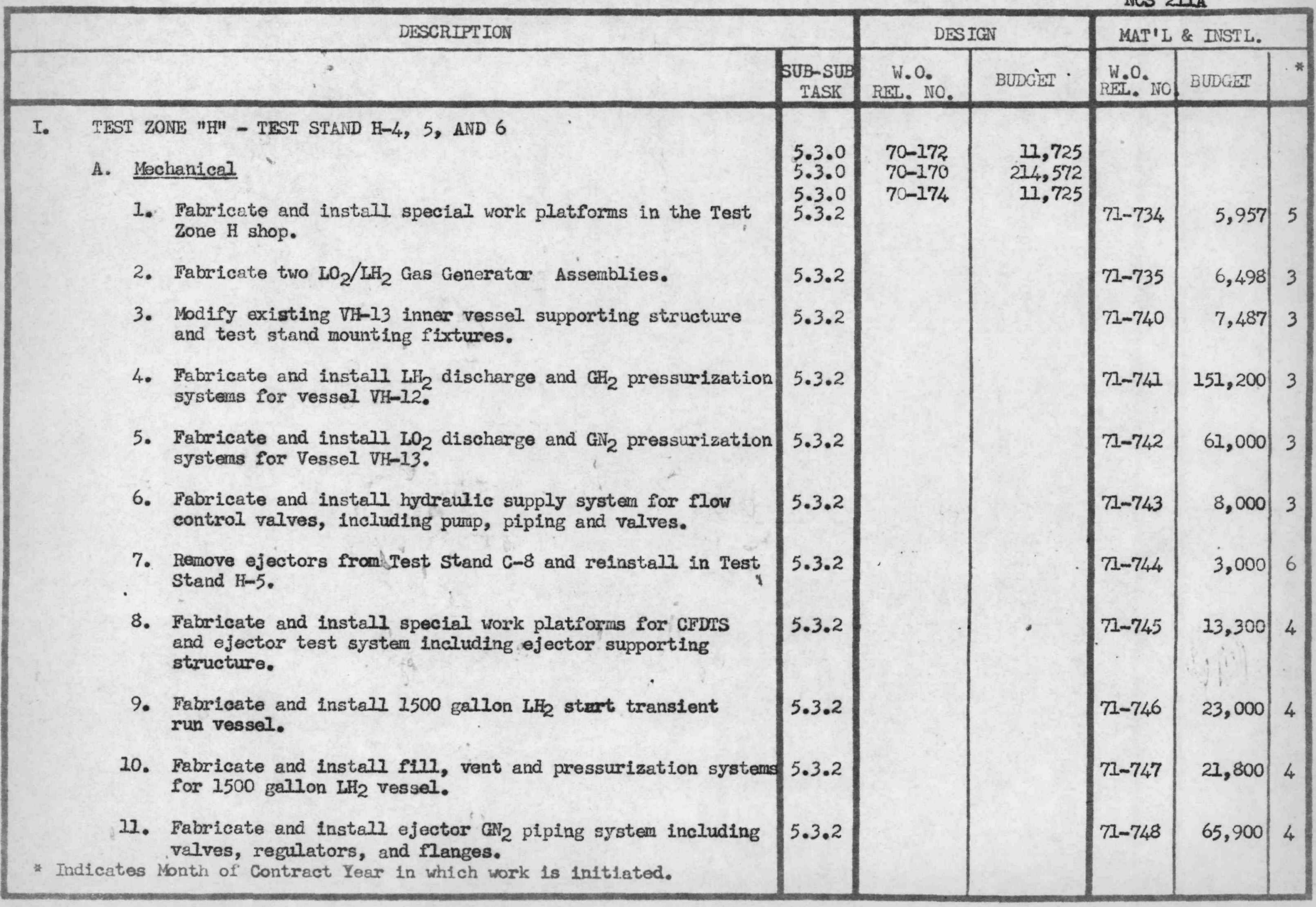




\begin{tabular}{|c|}
\hline DESCRTPTION \\
\hline 1,1
\end{tabular}

12. Fabricate and install special ducting to adapt between simulator interface and ejector inlet.

13. Fabricate and install a.hot hydrogen heat exchanger, including heating source. (10\#/sec. $1760^{\circ} \mathrm{R}$ )

14. Fabricate and instell heat exchanger supply and distribution piping.

15. Fabricate and install special turbine power control valve test fixture including hot gas supply and carry off ducting.

16. Fabricate and install nozzle adapter water coolant supply system.

17. Test Zone "H" Facility Activation.

18. Continuing test setup nodifications to accommodate test hardware configuration changes.

Sub Total

B. Instrumentation and controls

is 4

1. Fabricate and install additional drop boxes and electrical controls for Vessel VH-12 and TPCV test system.

2. Fabricate and install the ejector and simulator vessel electrical control systems.

3. Remove and relocate analog computer from Test Zone "C" to Test Zone "H".

4. Procure and install analog computer checkout equipment.

* Indicates Nonth of Contract Year in which work is initiated.

\begin{tabular}{|c|c|c|c|c|c|}
\hline & \multicolumn{2}{|c|}{ DESIGN } & \multicolumn{3}{|c|}{ MAT'I \& INSTL. } \\
\hline $\begin{array}{l}\text { SUB-SU: } \\
\text { TASK }\end{array}$ & $\begin{array}{l}\text { W.O. } \\
\text { REL. NO. }\end{array}$ & BUDGET & $\begin{array}{l}\text { W.O. } \\
\text { WEI. NO. }\end{array}$ & BUDGET & * \\
\hline 5.3 .2 & & & $71-749$ & 16,600 & 4 \\
\hline 5.3 .8 & . & & $72-401$ & 272,385 & 3 \\
\hline 5.3 .8 & ' & & $71-402$ & 68,000 & 5 \\
\hline 5.3 .2 & & & $71-410$ & 5,475 & 4 \\
\hline 5.3 .2 & & & $71-413$ & 16,000 & 3 \\
\hline 5.3 .2 & & & $71-736$ & 155,295 & 7 \\
\hline 5.3 .2 & & & $71-737$ & 45,608 & 5 \\
\hline & & 238,022 & & $\overline{946,445}$ & \\
\hline 5.3 .0 & $70-175$ & 100,983 & & & \\
\hline 5.3 .9 & & & $77-783$ & 3,600 & 3 \\
\hline 5.3 .9 & & & $71-784$ & 6,850 & 7 \\
\hline 5.3 .9 & & & $71-785$ & 38,765 & 8 \\
\hline 5.3 .9 & & & $71-786$ & 8,014 & 5 \\
\hline
\end{tabular}


NCS 27IA

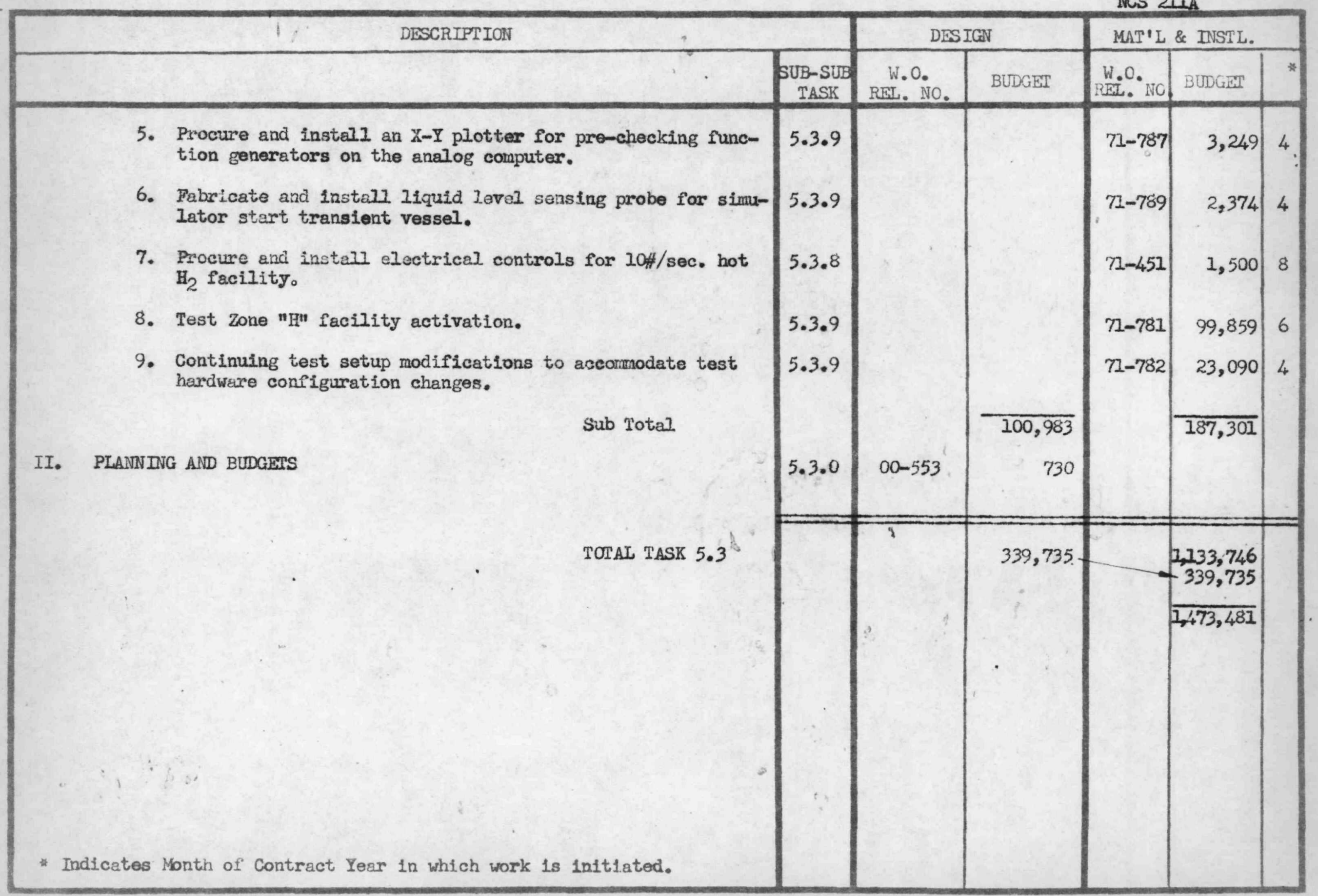


IRP NERVA Technical

Administration Document

Sub $\rightarrow$ Task Item 5.9

Contract Year 1963

15 November 1962

(NCS-211A)

1. TASK PITLE: SPECIAL T ST EQUIFMENT - LABORATORY FACILITIES - SACRAMENTO

2. EURPOSE AND OBJECTIVES:

The purpose of this sub-task is to provide for the design, procurement, fabrication, installation and activation of various laboratory Special Test Equipment necessary to the NERVA R\&D Program.

3. RELATED WORK AND BACKGROUND:

Continued utilization of the existing LRP Laboratory Facilities and STE, located in Building 2002, is planned for the NERVA Program dur = ing Contract Year 1963. These facilities and STE will continue to augment the capabilities provided within the new Cryogenics Laboratory.

4. DESCRIETION OF WORK FROGFAM

4.0 The Sub-Sub-Tasks of this Sub-Task are:

5.9.0 - STE Design and Construction Management

5.9 .1 - Vaxious Labaratory Mechanical STE

5.902 - Various Laboratory Instrumentation \& Controls STE

Ald of these sub-sub-tasks are under the cognizance of LRP.

These tasks are additional described in tabular form in

TabIe III - 5.9- The poliog and procedural requirements necessaxy to fulegniment of sub-tasks $2.6,402,4,2,4.3$ and 4.4 will be borne by this mub-task.

4.1 Sub-Sub-Task 5.9.0 - STE Design and Construction Management

Design effort asbociated with the laboratories consists of modifications necessary to equip the facilities for the special tests and studies planaed. Design effort will be initiated early in the time period and will continue during Contract Iear 1963 as required. Construction management efforts will consist of fabrication and installation coordination as required during this time period 
IRP NERVA Technical. Administration Document

Sub $=$ Task Item 5,9

Contract lear 1963

15 November 1962

(NCS-211A)

4.2 Sub-Sub-Task 5.9.1 a Various Laboratory Mechanical STE

a. The elctivities to be performed under this sub-sub-task duriag this tine period are:

(1) Fabrication and installation of an extension of the existing IN I $_{2}$ piping system for low temperature condition ing (Electrical Contols Loboratory)。

(2) Fabrication and installation of an environmental conditioning chamer (Electrical Controls Laboratory). (3) Fabrication and installation of special vibration equipment and fixtures (SRP Vibration Laboratory), (4) Contzauing test setup modifleations to accommodate test hardware configuration changes (All laboratories)

4.3 Sub-Sub- Pask 5.9,2 * Various Laboratory Instrumentation and Controls STE

a Contract Year 1963 activities on this sub-aub-task are:

(1) The installation of a speed sensor test setup

(Electrical Laboratory).

(2) The fabrication and installation of instrumentation

for acceptance tests of electrical components (Electrical Laboratory).

(3) Continuing equipment modifications or additions requj.red to acconmodate test hardware conflguration chamges (A.1. Laboratories). 


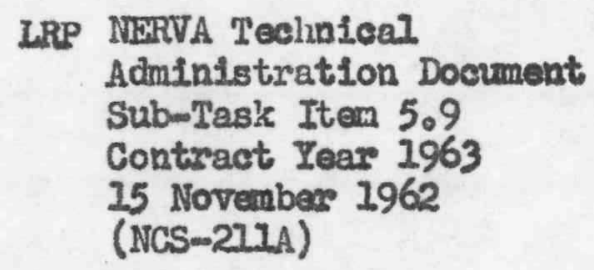

5. CONTRAGT YFAR 1962 CARRYOVER GTFORT

Contract Iear 1962 Coryryover Effort consists of those items of STE not completed during Conturact Year 1962 and requiring completion as part of the Contrect Iear 1963 effort. Active ongineering design, procurement, fabrication, and installation has been initiated on all items listed. 5.0 The continued Sub-Sub-Tasks of this Sub-Task are:

5.9.1 Contzrols and Chemistry Laboratory Mechanioal STE Complete fabrication and installation of gimbal test setup fixture。

5.9.2 Controls and Chamistry Laboratory Instrumentation and Controls STE Complete fabrication and installation of required instrumentation for gimbel test setup. 

NCS $211 \mathrm{~A}$

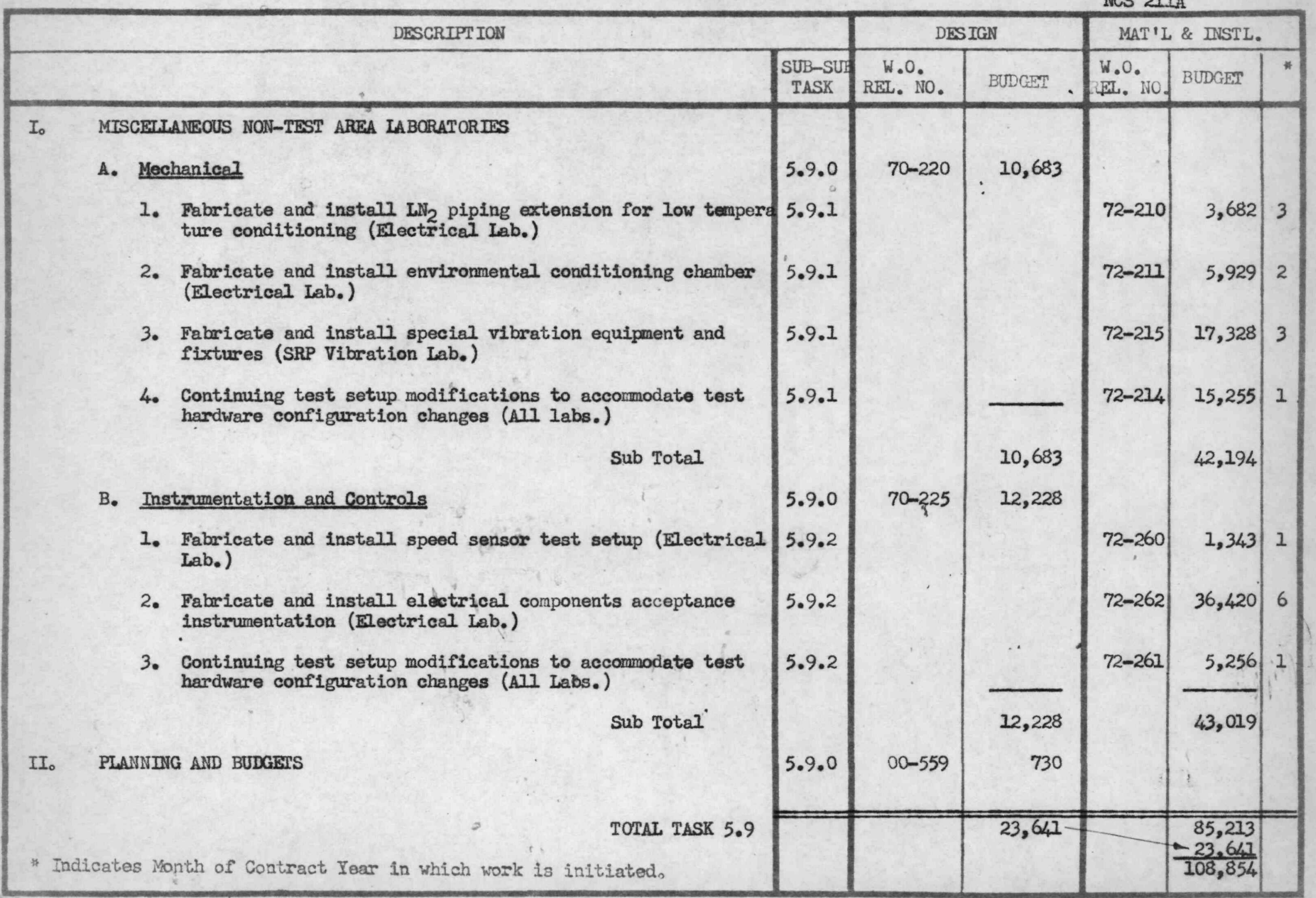


LRP NERVA Technical Administration Document Sub-Task Item 6.2 Contract Year 1963 15 November 1962

(NCS-211A)

1. TASK TIILE: OTHER GOVERNMFIT PROPARTY - TEST ZONE A - IRP

2. PURPOSE AND OBJEGT TVES:

The purpose of this sub-task is to provido for continued design, procurement, fabrication, and installation of government furnished facilitym type equipment to compliment and stpport the S.I. I. Installed in the Cryogenics Tuboratory. Provisioning of this equipment will be accomplished in an econonical, timely mannex consistent with the applicable milepost schedules。

3. BHEA IED WORK AND BACKGROUND:

The Cryogenjes Iaboratory was constructed for the NERVA Engine Program to implenent research and development in the field of exyogenics。 The activities of this laboretory ore being directed toward the development of Iiquid hydrogen engine components. The contimed provisioning of this laboratory with special tesi equipment for testing materials and components in a liquid hydrogen environment will avoid the necessity for improvised test setmups in the existing engineering Ieboritorles or in the high thrust test area. The goverment furnished equipment included in this submtask is required to complinent and support the developmeat program in the Gryogenies Iaboratory.

4. DISCRTPS TON OF WORK PROGRAM

4.0 The subm-sub-taslis of this sub-task are:

6.2.0 $\mathrm{O}_{0} \mathrm{GaP}$. Design and Consturution Management

6.2.1 Cryogenics Laborktory Mechanical O.G.P.

6.2.2 Gryogenics Laboratory Instxumentation and control $\mathrm{O}_{0} \mathrm{G}_{0} P_{0}$ 
INERVA Technical Administration Document

Sub-Task Item 6,2

Contract Year 1963

15 november 1962

(NCS-212A)

A]1 of these sub-subutasles are under the cognizance of LRP

These tasks are additlonally described in tabular form in

Table III - 6.2.

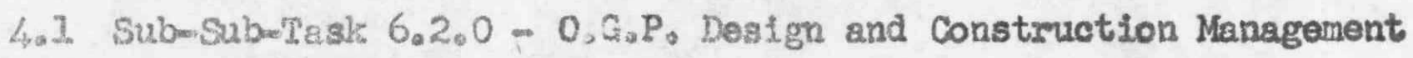

a. Mechanieal

(1) Activity for the government furnished equipment

will. Include Mechenical design of the following:

(a) Completion of the $\mathrm{LN}_{2}$ piping extension design.

(b) Completion of the humidity chamber design.

(c) Design of an LItz transfer piping system.

b. Instrumentation and Control

(1) Instrumentetion and control design activity will

Inolude the complete design of the fallowing cryogenic

Jaboratory equiprent:

(a) Design of mass spectromoter leak detectors.

(b) Completion of a precision voltmeter designo

(c) Final design and preparation of specifications

for procurement of a strain gage indicator, a frequence

convertor, five power supplies, an electrical spot

welder, an osstlloscope, a low frequency function

generator, and a residual gas analyser.

(a) Completion of a heat transfer apparatus power supply design。

c. Construction Managenent

(1) Constmuction manegenent services wil] asgure award of contracts to qualified low bidder and provide followup 
LRP NERVA Technical Adninistration Document

1 Subwask Iten 6.2

Contract Year 1963

15 Morember 1962

(NCS-221A)

recommended and approved as required.

402 Sub-Sub-Task 6.2.1 - Cryogenics Laboratory Mechanical $0_{3} G_{3} P_{0}$

(1) Activity during Contract Iear 1963 will include procurement and

Installation of the following machanical equipment in the Cryogenics Lab.

(a) $A n I N_{2}$ piping distribution system extension to supply the new onvironmental chambers.

(b) A 1000 Iiter portable IBl vessal to supply propellant to the specime

conditioning containers for tensile, fatigue and hardness testing.

(c) A humidity conditioning chamber for enviromental testing of

NERVA engine components。

4,3 Sub-Sub-Task $6.2,2$ - Gryogenies Laboratory Instrumentatiou and Control $0_{3} G_{3} P_{0}$

(1) The following Instrumentation and Control equipment will be fabricated and installed in the Cryogenics Laboratory during the contract year:

(a) A 400 cycle, variable frequency power supply for operation of the bearing test fisture drive motor.

(b) Two mass spectrometer loak detectors.

(c) A precision voltmoter.

(d) A strain gage indicator, a frequency converter, five power supplies, an electrieal spot welder, an oscilloscope, an oscillogram scanner, a Low froguency function generator, and rosidual gas analyzer.

(e) Two power supplies for operation of the heat transfer test apparatus.

(f) Additional removable patch boards to facilitate switching Instrumentation from one test bey to another. 
LRP NERVA Technical Administration Document Sub-Task Item 6.2 Contract Iear 1963

15 November 1962

(NCS-211A)

5. CONTRACT YEAR 1962 CARRYOVRR EKFYORT

Contract Year 1962 Carryover Effort consists of those items of OGP not completed during Contract Year 1962 and requiring completion as part of the Contrect Year 1963 effort. Active engineering design, procurement, fabrication, and installation has been initiated on all items listed. 5.0 The continued Sub-Sub-Task of this Sub-Task is: 6.2 .2 - Test Zone A - Cryogenic Laboratory, Instrumentation and Controls, $\mathrm{O}_{4} \mathrm{G} . \mathrm{P}_{0}$

Complete procurement and installation of all required signel conditioning and recording equipmento 
$R \vee A$

OTHER GOVERNMENT PROPERTY

TASK 6.2
TABIE II - 6.2-1

2. November 1962

CONIRACT YEAR 1963

NCS 27]A

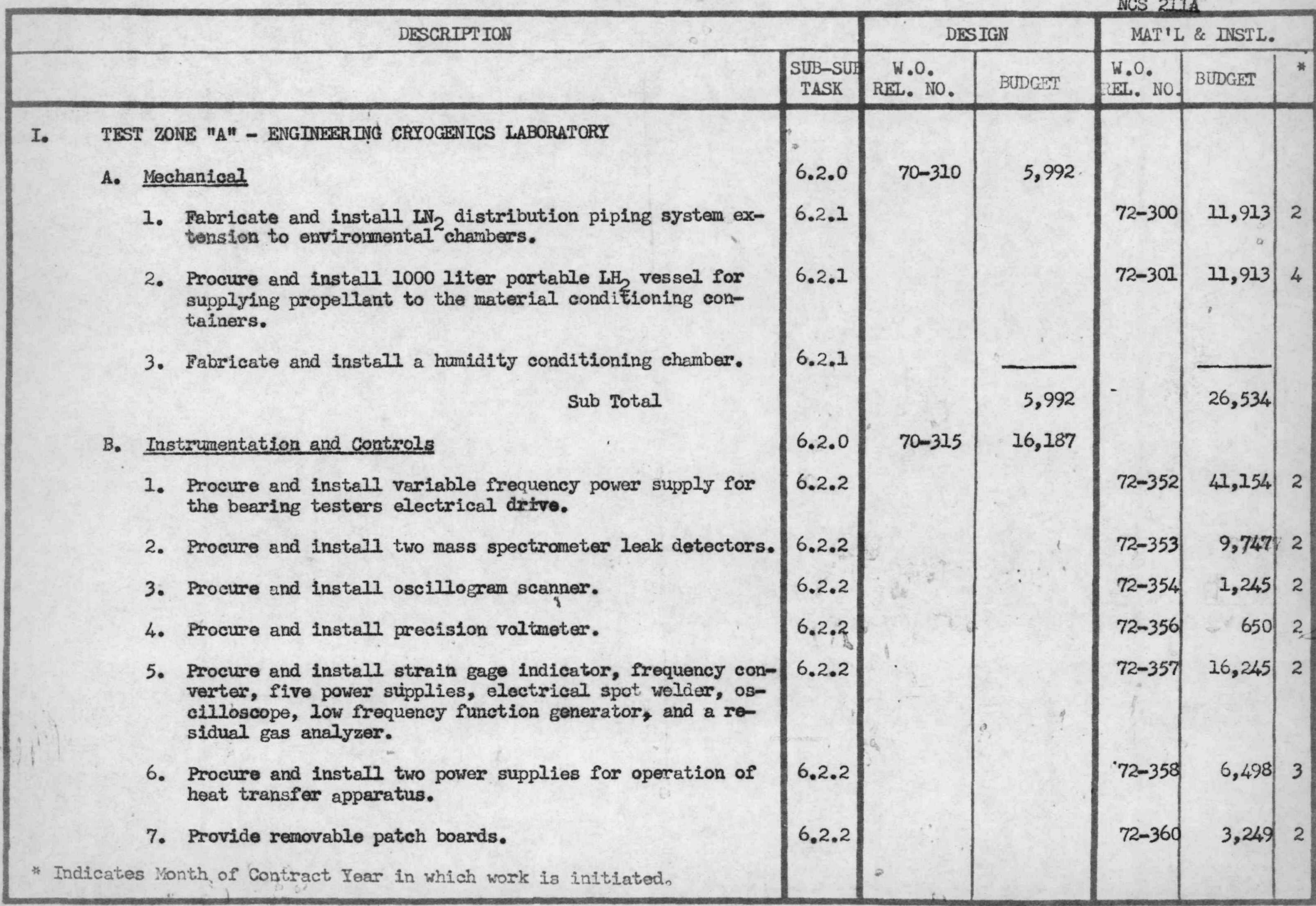




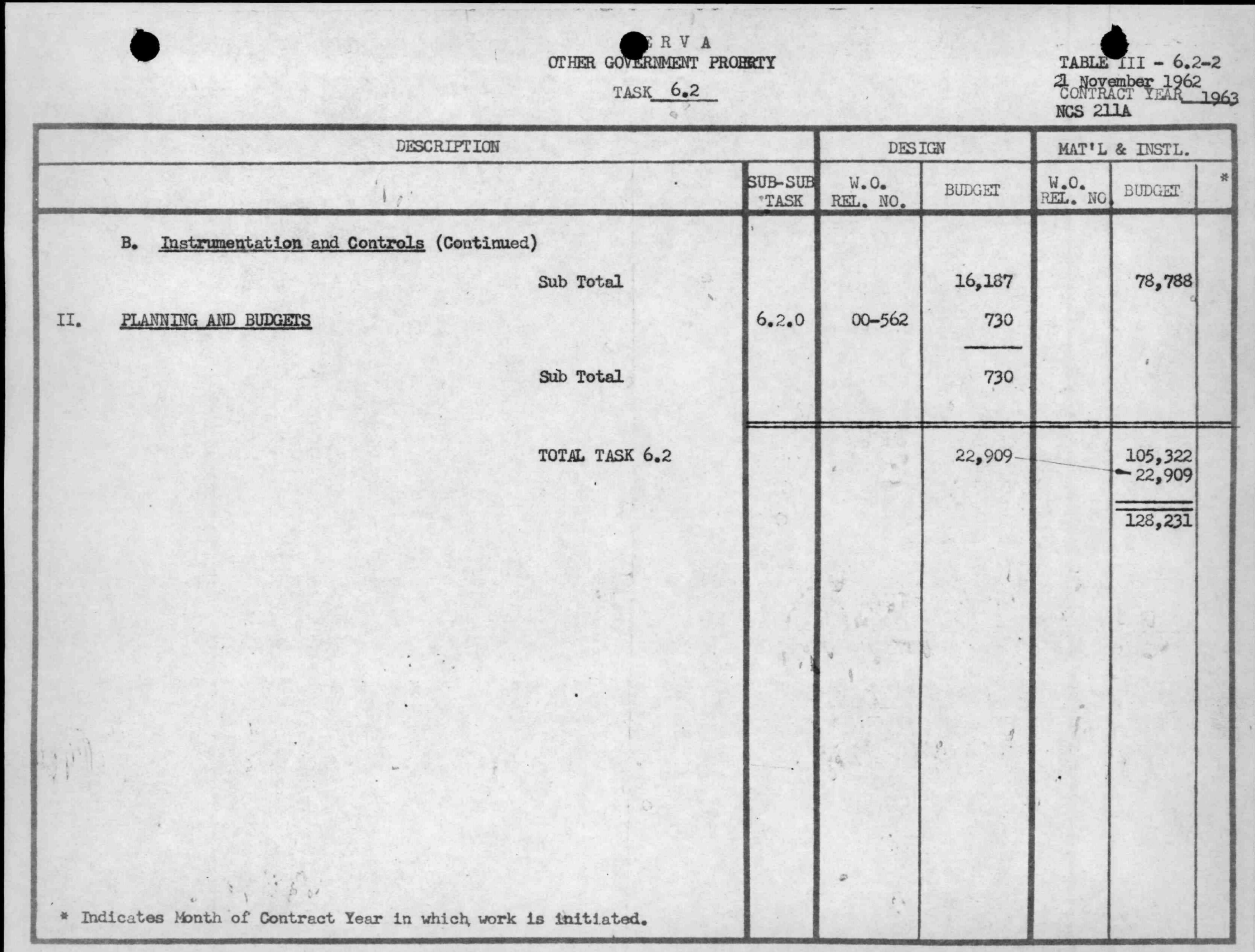

